\title{
DEMANDA DE CARNE BOVINA NO MERCADO BRASILEIRO
}

\section{MIRIAN RUMENOS PIEDADE BACCHI}

\author{
Orientador: Prof.Dr. Geraldo Sant'Ana de Camargo Barros
}

Dissertação apresentada à Escola Superior de Agricultura "Luiz de Queiroz", da Universidade de São Paulo, para obtenção do título de "Mestre" em Agronomia. AREA DE CONCENTRAÇÃO: Economia Agräria.

\author{
PIRACICABA \\ ESTADO DE SÃO PAULO - BRASIL \\ OUTUBRO DE 1989
}


Ficha catalográfica preparada pela Seção de Livros da

Divisão de biblioteca e Documentação - PCAP/USP

Bacchi, Mirian Rumenos Piedade

Bl16d Demanda de carne bovina no mercado brasileiro. Piracicaba, 1989.

$77 \mathrm{p}$. ilus.

Diss.(Mestre) - ESALQ

Bibliografia.

1. Carne bovina - Demanda - Brasil 2. Carne bovina Demanda - Elasticidade 3. Carne bovina - Mercado - Brasil 4. Mercado agricola - Brasil I. Escola Superior de Agricultura Luiz de Queiroz, Piracicaba

CDD 338.4766492 


\section{DEMANDA DE CARNE BOVINA NO MERCADO BRAS ILEIRO}

MIRIAN RUMENOS PIEDADE BACCHI

Aprovada em: 07.06 .1990

Comissão julgadora:

Prof. Dr. Geraldo Sant-Ana de Camargo Barros

ESALQ/USP

Prof. Dr. Evaristo Marzabal Neves

ESALQ/USP

Dr. Flāvio Condê de Carvalho

IEA / SP

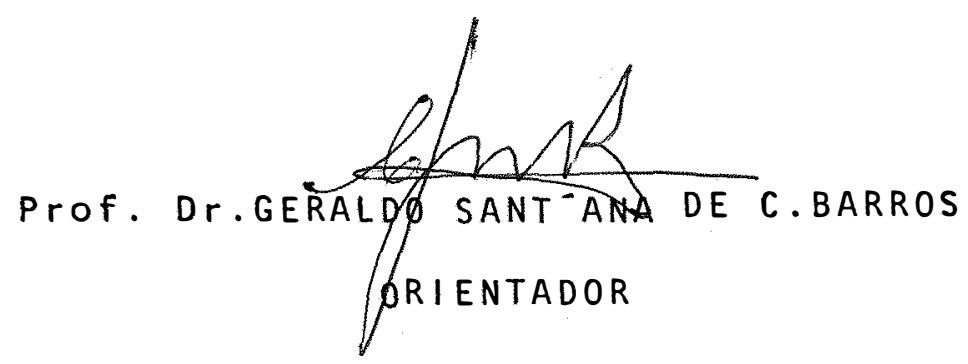


Aos meus pais Alvaro e Susana Ao Osny, Fernanda e Isabela 
AGRADECIMENTOS

Ao Prof. Geraldo Sant'Ana de Camargo Barros pela eficiente orientação dada na realização deste trabalho.

Aos Profs. Evaristo Marzabal Neves, José Ferreira de Noronha, Fernando Curi Peres e Rodolfo Roffmann pelas valiosas críticas e sugestões apresentadas para o aperfeiçoamento do texto original.

A Ana Lúcia Kassouf pela amizade e colaboração no processamento dos dados.

A todos os membros do Departamento de Economia e em especial ao Dr. Paulo Fernando Cidade de Araujo, cujo estímulo foi de grande valia.

A FIPE - Fundação Instituto de Reqquisas Econômicas da USP pela cessão dos dados utilizados.

A todos que direta ou indiretamente contribuiram para que este trabalho fosse realizado. 
CONTEUDO

Pägina

LISTA DE TABELAS $\ldots \ldots \ldots \ldots \ldots \ldots \ldots \ldots \ldots \ldots \ldots \ldots \ldots \ldots \ldots \ldots \ldots \ldots \ldots \ldots \ldots$

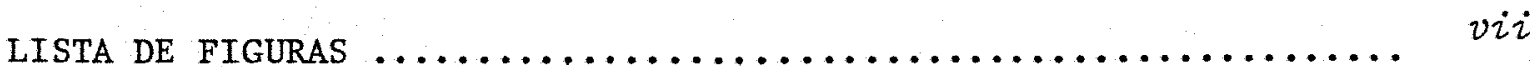

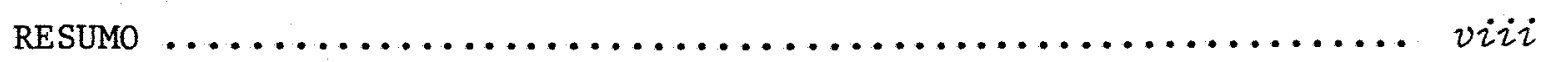

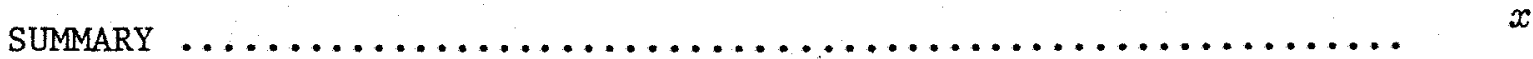

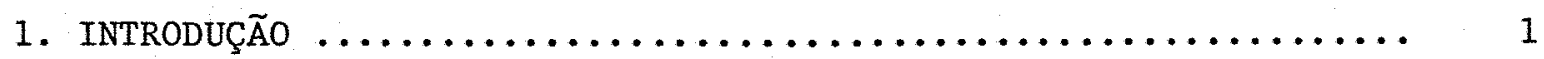

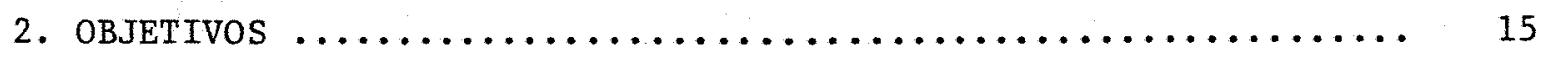

3. METODOLOGIA ............................. 17

3.1. Modelos Integracionistas $\ldots \ldots \ldots \ldots \ldots \ldots \ldots \ldots \ldots \ldots \ldots$

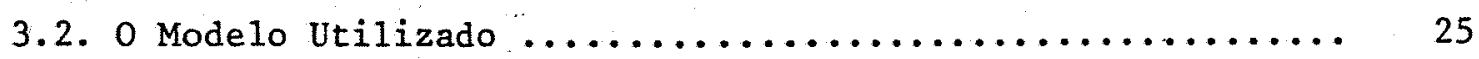

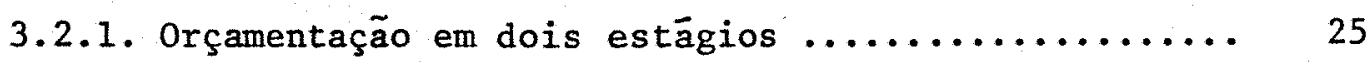

3.2.2. Modelo de Defasagem Distribuỉda ............. 27

3.2.3. Teste de Causalidade ................... 30

3.2.4. Especificação Empĩrica ................ 35

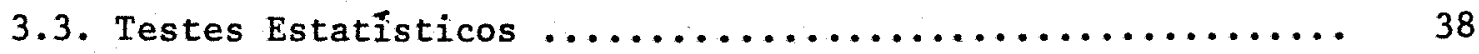

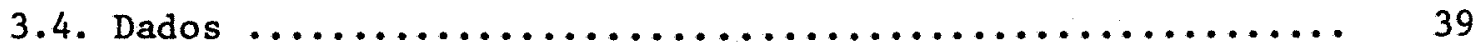

4. RESULTADOS E DISCUSSÃo ........................ 43

4.1. Anālise da Evolução do Mercado de Carne Bovina -

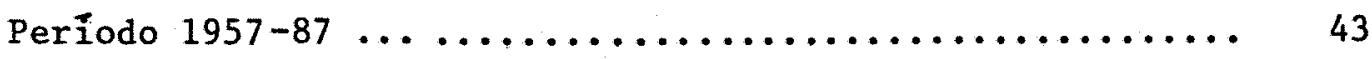

4.2. Anālise Estatística ...................... 51

4.3. Anālise Econômica ......................... 57

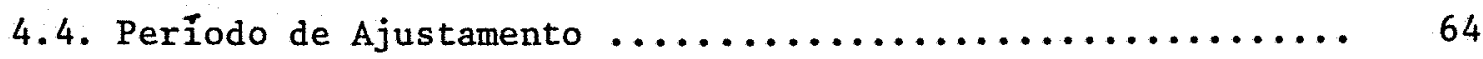

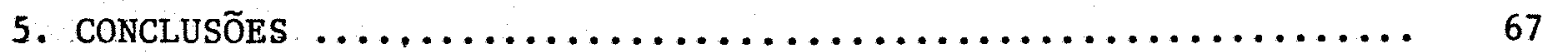

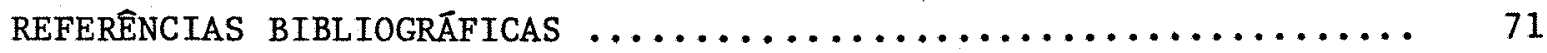


LISTA DE TABELAS

Tabela no

Pāgina

1 Relação entre salário mínimo/preço real de carne bovina para o período $1971-87 \ldots \ldots \ldots \ldots \ldots \ldots \ldots \ldots \ldots \ldots$

2 Média anual de preços reais de varejo das carnes de boi, porco e frango na ciade de são Paulo, para o

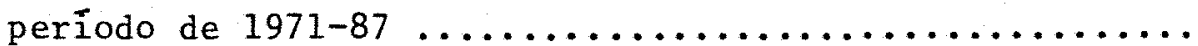

3 Disponibilidade "per capita" de diferentes carnes (Kg) no Brasi1, para o período $1970-87 \ldots \ldots \ldots \ldots \ldots \ldots \ldots \ldots \ldots$

4 Coeficientes das regressões : consumo de carne bovina versus preço de carne bovina, preço de carne suĩna, preço de frango e renda (incluindo a variāvel binária e suas interações). Período 1957-87 ..........

5 Estimativa dos coeficientes da função de demanda de carne bovina para o mercado brasileiro, Estatísticas " $t$ ", "F" e " $Q$ " e Coeficientes de Determinação da Fun ção Especificada. Período 1957-87 ................

6 Estimativa dos Coeficientes da função de demanda de carne bovina para o mercado brasileiro, Estatísticas " $t$ ", "F" e "Q" e Coeficientes de Determinação da Fun ção Modificada. (Com constante e a renda expressa nos logaritmos dos valores observados). Período 1957-87

7. Elasticidades de demanda de carne bovina calculadas nas médias amostrais para curto e longo prazos e fór mulas utilizadas para a obtenção dessas elasticidades ... 
8 Elasticidades-preço direta da demanda de carne bovina para o Brasil e regiões específicas do Brasil ....... 60

9. Elasticidades-renda da demanda de carne bovina para - Brasil e regiões específicas do Brasil ............ 63

10 Elasticidades de demanda de carne bovina calculadas nas médias amostrais para curto e longo prazos com a função modificada (com constante e renda expressa nos logaritmos dos valores observados) $\ldots \ldots \ldots \ldots \ldots \ldots \ldots$ 
Figura no

Pāgina

1 Quantidade consumida de carne bovina versus preço de carne bovina - periodo $1957-87 \ldots \ldots \ldots \ldots \ldots \ldots \ldots . \ldots 44$

2 Quantidade consumida de carne bovina versus preço de carne suína - período $1957-87 \ldots \ldots \ldots \ldots \ldots \ldots \ldots . \ldots 44$

3 Quantidade consumida de carne bovina versus renda-

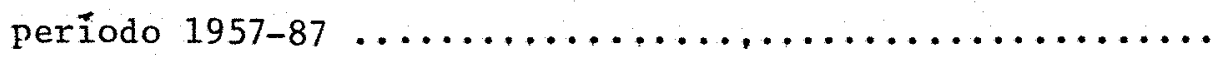

4 Quantidade consumida de carne bovina versus preço de frango - período 1957-87

5 Quantidade consumida de carne de frango versus pre-

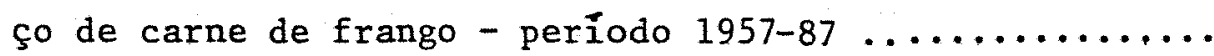


DEMANDA DE CARNE BOVINA NO MERCADO BRASILEIRO

Mirian Rumenos Piedade Bacchi

Orientador: Geraldo Sant'Ana de Camargo Barros

RESUMO

o objetivo principal do presente estudo foi o de obter as elasticidades da demanda de carne bovina no mercado brasileiro.

o modelo utilizado para a obtenção dessas elasticidades segue uma abordagem integracionista (considera a inter-relação de todos os bens e serviços) e se fundamenta no conceito de separabilidade homogênea da função de utilidade.

Com dados do período 1957-87, a função de demanda foi ajustada pelo método de mínimos quadrados, com as variāveis expressas nos números naturais.

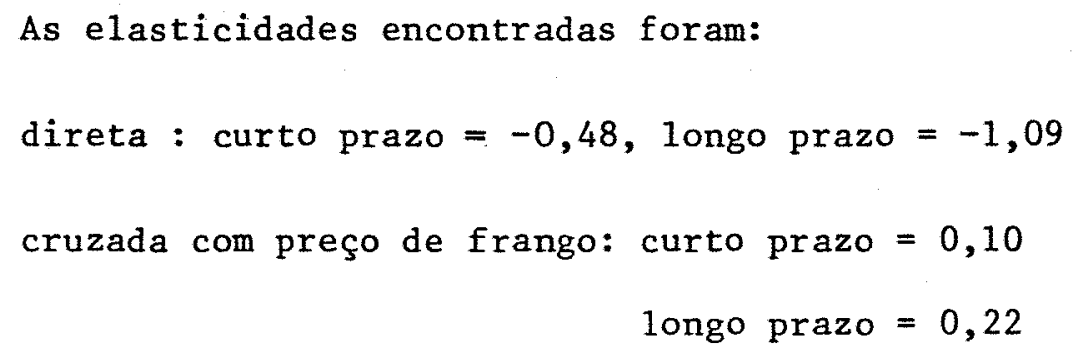


cruzada com preço de suíno: curto prazo $=0,33$

$$
\text { longo prazo }=0,73
$$

renda: curto prazo $=0,30$, longo prazo $=0,67$

o coeficiente da variāvel preço de frango apresentou-se não significativo o que atribuiu-se a problemas de ordem econométrica ou de qualidade dos dados utilizados.

As elasticidades de curto prazo encontradas permitem concluir que variações na renda dos consumidores têm baixa influência no consumo de carne bovina. Conquanto o sinal positivo do coeficiente da variavel preço de carne suína indique que esta carne e a bovina sejam produtos substitutos, verifica-se que o consumo de carne bovina é tambêm pouco sensîvel às variações nos preços de carne suína.

A quantidade demandada de carne bovina è mais sensível às variações ocorridas em seu preço, no preço de carne suína e na renda dos consumidores à medida que o tempo se alonga.

o valor do coeficiente de ajustamenteo $(\delta)$, calculado a par tir do coeficiente da variável consumo de carne bovina defasado, indica que $44,4 \%$ da diferença entre a demanda observada e a desejada é eliminada em um período. 0 tempo necessário para a demanda observada atingir $98 \%$ da desejada, foi calculado em 6 anos e 8 meses. 
Mirian Rumenos Piedade Bacchi Adviser: Geraldo Sant'Ana de Camargo Barros

SUMMARY

The main objective of this study was to determine beef demand elasticities for Brazilian market.

The model used obtainning the elasticities is based on the integrationist approach that recognizes the interrelationship among all commodities, and on the concept of homogeneous separability of the utility function.

Data from the 1957-87 period, expressed in terms of natural numbers, were adjusted by the ordinary least square method. The results estimated for demand elasticities were:

$$
\begin{aligned}
\text { Direct elasticity: short term }=.48, \text { long term } & =1.09 \\
\text { Cross elasticity with chicken meat: } & \text { short term }=.10 \\
& \text { long term }=.22
\end{aligned}
$$


Cross elasticity with pork meat: short term $=.33$

$$
\text { long term }=.73
$$

Income elasticity: short term $=.30$, long term $=.67$

Although the chicken price coefficient in the equation was not significant, we tend to believe that either econometric problems or data quality didn't allow the detection of correlation between this variable and beef consumption.

The short term elasticity values found allow us to conclude that variations in income have little influences of beef consumption. Although the positive sign of the pork price coefficient indicates that beef and pork are substitute products, it can be observed that beef consumption is also little sensible to pork price variations.

Beef consumption is more sensible to its own price variations, pork price and income, in the long run.

The adjustment coefficient value $(\delta)$, calculated from the lagged beef consumption coefficient, indicates that $44.4 \%$ of the difference between observed and desired demand is eliminated in one period. The period required for the observed demand to reach $98 \%$ of the desired demand was estimated to be 6 years and 8 months. 
1. INTRODUÇÃO

o conhecimento dos principais determinantes do funcionamento de mercado de produtos agrícolas é de grande importância para o estabelecimento de políticas econômicas que visem evitar flutuações indesejadas de preço, bem como para o delineamento de programas especiais de nu trição, abastecimento etc.. Em particular, as elasticidades de oferta e demanda, constituem-se em importantes instrumentos de orientação para o planejamento da produção, polîticas agrícolas, consumo e exportação.

Dentre os produtos agrícolas, aqueles de alto teor protéico apresentam peso significativo na parcela do orçamento do consumidor brasileiro destinada à alimentação e consequentemente na ponderação dos Indices de preços indicadores da inflação. Dentro dessa categoria, a car ne bovina ocupa posição de destaque, em termos de consumo, constituindose ainda em produto de certa relevância no conjunto de bens exportáveis.

o setor de pecuária bovina apresenta, no Brasil, um ritmo de desenvolvimento relativamente incipiente, gerado pela pequena taxa de incorporação de tecnologia e consequente baixa produtividade do rebanho ${ }^{1}$. $\overline{1 \text { MOREIRA }}$ (1980). 
Isso tem impedido o país de alcançar um volume de produção de carne bovina suficiente para suprir o mercado interno à preço acessível, às populações de menor renda e dinamizar as exportações visando a consolidação da posição de exportador jā conseguida.

A nossa pecuária de corte caracteriza-se por um comportamento cíclico que pode ser evidenciado pela evolução dos abates. A carne bovina, como relatado por vārios autores, entre eles MASCOLO (1980), NEVES et alii (1985), AZEVEDO FILHO et a $i$ ii (1987), MUELLER (1987) e KASSOUF (1988), tem ciclo de produção com fortes oscilações plurianuais (ciclo do gado) e destacada flutuação sazonal derivada da época de safra e entre-safra, acarretando substanciais variações nos preços. Essa peculiaridade da bovinocultura, aliada às ações intervencionistas do governo, às vezes imediatistas e não articuladas com uma orientação global de desenvolvimento do setor, aumentando os riscos e gerando incertezas, tem sido apontadas como responsáveis pela resposta inadequada dos pecuaristas às pressões de demanda ${ }^{2}$.

Essas condições tēcnico-econômicas desfavorāveis para o setor têm resultado em diminuição no consumo de carne bovina e favorecido o crescimento da produção de carnes substitutas. Em tempos recentes, pa ralelamente à queda dos salários reais, tem-se observado uma evolução desfavorável nos preços da carne bovina em relação a outro tipo de carne. Isso só tem levado a deslocamentos na função de demanda daquele produto, com acomodação do consumo à oferta disponỉvel.

${ }^{2}$ Ver MUELLER (1987). 
Na Tabela 1 são apresentados dados sobre preço de carne bo vina no varejo, para a cidade de São Paulo, e salário mínimo, verificando-se que no período 1971-87 houve significativas modificações no poder de compra do salário mínimo em relação ao preço deste alimento. os cinco ültimos anos da série apresentaram, juntamente com os anos de 1979 e 1980, os menores valores da relação salário mínimo/preço de carne bovina (no de quilos de carne bovina comprados com 1 salário mínimo).

A relação entre os preços das diferentes carnes, que pode ser visualizada na Tabela 2, evidencia, para todos os anos da série, após 1972, a desvantagem econômica advinda da aquisição de carne bovina comparativamente à carne de frango. Em relação a carne suína observa-se alternância de períodos em que esta apresentou-se com maior ou menor vantagem econômica que a carne bovina. Comparativamente à carne de frango, a carne suỉna apresentou-se desvantajosa economicamente para todos os anos da sêrie após 1972. 
Tabela 1. Relação entre salário mínimo/preço real de carne bovina para o período $1971-87$

\begin{tabular}{|c|c|c|c|c|}
\hline \multirow{2}{*}{ Ano } & \multirow{2}{*}{$\begin{array}{l}\text { Valor real do } \\
\text { salário mínimo } \\
\quad(\mathrm{Cz} \$)(1)\end{array}$} & \multirow{2}{*}{$\begin{array}{l}\text { Preço real de } \\
\text { carne bovina } \\
(\mathrm{Cz} \$ / \text { quilo })\end{array}$} & \multicolumn{2}{|c|}{ Relação SM/carne bovina } \\
\hline & & & Valor & Indice \\
\hline 1971 & $6.326,12$ & 146,81 & 43,09 & 100,00 \\
\hline 1972 & $6.453,12$ & 145,84 & 44,25 & 102,69 \\
\hline 1973 & $6.565,14$ & 194,58 & 33,74 & 78,30 \\
\hline 1974 & $6.171,39$ & 205,52 & 30,03 & 69,69 \\
\hline 1975 & $6.600,14$ & 184,04 & 35,86 & 83,22 \\
\hline 1976 & $6.522,39$ & 170,59 & 38,23 & 88,72 \\
\hline 1977 & $6.585,25$ & 167,09 & 39,41 & 91,46 \\
\hline 1978 & $6.728,48$ & 201,27 & 33,43 & 77,58 \\
\hline 1979 & $6.673,61$ & 250,99 & 26,59 & 61,71 \\
\hline 1980 & $6.285,66$ & 224,49 & 27,10 & 62,89 \\
\hline 1981 & $6.070,59$ & 181,11 & 33,52 & 77,79 \\
\hline 1982 & $6.186,86$ & 162,77 & 38,01 & 88,21 \\
\hline 1983 & $5.322,20$ & 183,14 & 29,06 & 67,44 \\
\hline 1984 & $4.461,62$ & 185,44 & 24,06 & 55,84 \\
\hline 1985 & $4.544,27$ & 158,65 & 28,64 & 66,47 \\
\hline 1986 & $4.515,61$ & 164,60 & 27,43 & 63,66 \\
\hline 1987 & $3.740,25$ & 173,90 & 21,51 & 49,92 \\
\hline
\end{tabular}

Fonte: os preços de carne bovina foram obtidos a partir dos preços mensais dos diversos cortes que compõem a carcaça do boi, preços estes fornecidos pela FIPE - Fundação Instituto de Pesquisas Econômicas-USP, ponderados pela participação do corte no total da carcaça, conforme Sistema Ponderal de Conversões publicado pelo ITAL, CANTo, 1988. Os dados sobre salärio mínimo do Estado de S.Paulo foram extraídos de Conjuntura Econômica, 1971-87.

(1) Inclue o 139 salärio.

Valores de salário mínimo e preço de carne bovina corrigidos pelo IGPIndice Geral de Preços da FGV para dezembro de 1987. 
Tabela 2. Média anual de preços reais de varejo das carnes de boi, porco e frango na cidade de São Paulo, para o período de 1971-87

\begin{tabular}{|c|c|c|c|c|c|c|}
\hline \multirow{2}{*}{ Ano } & \multicolumn{3}{|c|}{ Preços das carnes (Cz\$/quilo)* } & \multicolumn{3}{|c|}{ Razão de preços } \\
\hline & Boi(1) & Porco (2) & Frango(3) & $(2) /(1)$ & $(3) /(1)$ & $(3) /(2)$ \\
\hline 1971 & 146,81 & 144,72 & 217,58 & 0,98 & 1,48 & 1,50 \\
\hline 1972 & 145,84 & 171,56 & 187,78 & 1,18 & 1,29 & 1,09 \\
\hline 1973 & 194,58 & 202,87 & 146,35 & 1,04 & 0,75 & 0,72 \\
\hline 1974 & 205,52 & 250,06 & 142,16 & 1,22 & 0,69 & 0,57 \\
\hline 1975 & 184,04 & 211,06 & 131,53 & 1,15 & 0,71 & 0,62 \\
\hline 1976 & 170,59 & 186,53 & 128,53 & 1,09 & 0,75 & 0,69 \\
\hline 1977 & 167,09 & 204,67 & 119,31 & 1,22 & 0,71 & 0,58 \\
\hline 1978 & 201,27 & 202,69 & 130,91 & 1,01 & 0,65 & 0,65 \\
\hline 1979 & 250,99 & 223,24 & 140,68 & 0,89 & 0,56 & 0,63 \\
\hline 1980 & 224,49 & 196,34 & 119,27 & 0,87 & 0,53 & 0,61 \\
\hline 1981 & 181,11 & 154,44 & 105,73 & 0,85 & 0,58 & 0,68 \\
\hline 1982 & 162,77 & 167,83 & 91,94 & 1,03 & 0,56 & 0,55 \\
\hline 1983 & 183,14 & 173,53 & 104,18 & 0,95 & 0,57 & 0,60 \\
\hline 1984 & 185,44 & 172,25 & 110,55 & 0,93 & 0,60 & 0,64 \\
\hline 1985 & 158,65 & 169,98 & 99,31 & 1,07 & 0,63 & 0,58 \\
\hline 1986 & 164,60 & 169,85 & 111,27 & 1,03 & 0,68 & 0,66 \\
\hline 1987 & 173,90 & 144,25 & 95,27 & 0,83 & 0,55 & 0,66 \\
\hline
\end{tabular}

Fonte: FIPE/USP (preço de frango). Preços de suino e bovino obtidos a partir dos preços mensais dos diversos cortes que compõem a carcaça desses animais (fornecidos pela FIPE) ponderados pela participaçao do corte no total da carcaça, conforme Sistema Ponderal de Conversões publicado pelo ITAL, CANTO, 1988.

* Corrigido pelo IGP para dezembro de 1987. 
Em 1971, o preço do quilo da carne de frango no varejo correspondia a aproximadamente $148 \%$ do preço do quilo da carne bovina, passando a valores relativos menores nos outros anos da sériede modo que, em 1987, o preço da carne de frango correspondia a $55 \%$ do preço da carne bovina. As alterações ocorridas na relação preço de carne de frango/preço de carne suína foram também significativas. No ano de 1971 o preço da carne de frango equivalia à $150 \%$ do preço da carne suína e, em 1987, essa equivalência diminuiu para $66 \%$.

A participação da carne bovina no consumo "per capita", den tro desse grupo de carnes mais consumidas, baixou de $65,2 \%$, em 1970, para 41,8\% em 1987, sendo o aumento do consumo da carne de frango o maior responsável por essa alteração de valores. (ver Tabela 3).

Ao contrārio da bovinocultura que não tem obtido resultados tecnológicos expressivos e onde a absorção de tecnologia não tem sido uniforme para as diferentes zonas criatórias, a avicultura tem acompanhado, no mesmo nível, os avanços tecnológicos dos países desenvolvidos, que são os grandes produtores mundiais de carne de frango.

0 crescimento do consumo da carne de frango vem do início dos anos 70, mas a tendência de equiparação com o de carne vermelha só veio a se configurar na presente década.

o desenvolvimento da avicultura, ocorrido no período 197087, fica evidenciado ao verificar-se que a produção de carne de frango era de somente 0,21 milhão de toneladas, em 1970, passando a 1,75 milhão de tone ladas, em 1987. Considerando-se que, em 1987, somente 220.000 toneladas foram exportadas, tem-se um consumo "per capita" de aproximadamente $11 \mathrm{~kg}$ neste ano, pela primeiravez muito próximo ao da carne bovina ${ }^{3}$.

$\overline{3 \text { MOLINARI }}$ (1988). 
Tabela 3. Disponibilidade "per capita" de diferentes carnes (Kg) no Brasil, para o período 1970-87

\begin{tabular}{|c|c|c|c|c|}
\hline Ano & Carne bovina & Carne de frango* & Carne suína & Total \\
\hline 1970 & $18,3 \quad(65,2)$ & $2,2(7,8)$ & $7,6 \cdot(27,0)$ & 28,1 \\
\hline 1971 & $17,4(63,3)$ & $2,2(8,0)$ & $7,9(28,7)$ & 27,5 \\
\hline 1972 & $17,7(64,9)$ & $2,9(10,6)$ & $6,7 \quad(24,5)$ & 27,3 \\
\hline 1973 & $18,2(62,5)$ & $3,9(13,4)$ & $7,0(24,1)$ & 29,1 \\
\hline 1974 & $19,6 \quad(62,9)$ & $4,6 \cdot(14,7)$ & $7,0(22,4)$ & 31,2 \\
\hline 1975 & $15,9(57,0)$ & $4,8(17,2)$ & $7,2(25,8)$ & 27,9 \\
\hline 1976 & $18,4(59,7)$ & $5,2 \quad(16,9)$ & $7,2(23,4)$ & 30,8 \\
\hline 1977 & $20,0 \quad(60,2)$ & $5,8 \quad(17,5)$ & $7,4(22,3)$ & 33,2 \\
\hline 1978 & $19,7 \quad(56,6)$ & $6,9 \quad(19,8)$ & $7,5(21,6)$ & 34,8 \\
\hline 1979 & $16,4(50,5)$ & $8,4(25,8)$ & $7,7 \quad(23,7)$ & 32,5 \\
\hline 1980 & $16,2(48,5)$ & $9,1 \quad(27,2)$ & $8,1(24,3)$ & 33,4 \\
\hline 1981 & $15,2(46,9)$ & $9,3(28,7)$ & $7,9(24,4)$ & 32,4 \\
\hline 1982 & $16,3(48,1)$ & $10,0(29,5)$ & $7,6(22,4)$ & 33,9 \\
\hline 1983 & $14,9(46,6)$ & $9,6(30,0)$ & $7,5(23,4)$ & 32,0 \\
\hline 1984 & $13,0(46,3)$ & $7,9(28,1)$ & $7,2(25,6)$ & 28,1 \\
\hline 1985 & $13,3(45,5)$ & $8,6(29,5)$ & $7,3(25,0)$ & 29,2 \\
\hline 1986 & $14,8(45,1)$ & $9,7 \quad(29,6)$ & $8,3(25,3)$ & 32,8 \\
\hline 1987 & $14,1 \quad(41,9)$ & $10,8(32,0)$ & $8,8(26,1)$ & 33,7 \\
\hline
\end{tabular}

Fonte: IBGE-Instituto Brasileiro de Geografia e Estatística (ANUĀRIO ESTATISTICO) e Ministério da Fazenda e CACEX para dados que geraram o de disponibilidade de carne bovina. Os dados de disponibilidade de carne suina e de frango foram extraídos do Boletim ETAC MERCADOS - Carnes.

* Disponibilidade de carne de frango estimada com base na disponibilidade de carne de aves considerando um fator de conversão de $0,97^{4}$.

- Os dados entre parênteses indicam a participação da disponibilidade de cada carne no total do grupo.

4 AVICULTura, Agroanázysis, 1988. 
Esse efeito de substituição da carne bovina, num contexto de tendência de aumento de consumo "per-capita" de carnes, explica porque seus preços, na década de 80 , não sofreram a pressão de alta esperada em decorrência da queda na sua disponibilidade interna.

Dada a importância da análise do comportamento do mercado de carne bovina e, em particular, a obtenção dos parâmetros da sua função de demanda, vários pesquisadores brasileiros têm abordado a questão.

PEREZ (1973) através de dados de corte transversal no tempo, obtidos no més de julho de 1971, com amostra consistindo de 255 familias da cidade de Piracicaba-SP (pertencentes a diversas classes de renda), estimou, entre outras elasticidades, a elasticidade renda para diversas categorias de alimentos. Utilizando o método de mínimos quadrados ordinários para o ajuste da função da demanda que foi especificada na forma bi-logarítmica, obteve o valor de 0,77 para a elasticidade renda da demanda de carne bovina de primeira.

ÁVILA (1973) estimou, a partir de dados de série anual do período 1947-70, equações de oferta de bovinos para abate e demanda de carne bovina para o Rio Grande do Sul. As equaçōes foram ajustadas pelo mêtodo dos mínimos quadrados ordinários, com as variáveis expressas nos 1ogarítmos decimais dos valores observados. Os resultados mostraram que a demanda estadual de carne bovina era inelástica em relação a preço, tanto a curto prazo $(-0,49)$, quanto a longo prazo $(-0,64)$. Os resultados encontrados para as elasticidades-renda foram de 0,26 e 0,36 no curto e longo prazos, respectivamente. 
BRANDT et alii (1973), utilizando dados mensais do período janeiro 1970 a dezembro de 1972 e trabalhando com um sistema de equações simultâneas ajustadas pelo método dos mínimos quadrados de dois estāgios (Theil - Bassman), analis aram a estrutura de mercado consumidor de carne bovina de Manaus, Amazonas. Concluíram que a demanda de carne bovina era preço-inelástica $(-0,6)$ e renda-elástica $(2,6)$. Concluíram ainda que não havia influência significativa das variações em preço de pescado e de carne de aves sobre o consumo de carne bovina.

SERAPHIM (1973) ajustou, pelo método dos mínimos quadrados ordinários, equaçōes de demanda de carne bovina, suína e de aves para a cidade de Goiânia, Goiás, utilizando dados mensais do período de 196972. Os resultados encontrados foram: elasticidades-preço da demanda de carne bovina iguais a $-0,69$ e $-1,07$ no curto e longo prazos, respectivamente, e elasticidades-renda iguais a 0,23 e 0,36 no curto e longo prazos, respectivamente. 0 período de tempo previsto para a procura observada se ajustar a uma proporção da procura desejada, tomada nesse estudo como $98 \%$, foi estimado em 4 meses.

SANTOS et alii (1974), utilizando dados de corte seccional de 1974, na cidade de São Luiz, Maranhão, estimaram, pelo método dos mínimos quadrados ordinários, equações de demanda de carne bovina, carne suína e de pescado. Verificaram que a demanda de carne bovina era preço-elástica $(-1,35)$, apresentava pouca sensibilidade às variações de preço de carne suína $-0,25)$ e era renda-inelástica $(0,66)$.

FURTUOSO (1981) com a finalidade de determinar o efeito da redistribuição da renda disponível sobre a demanda de alimentos no Estado de São Paulo, conduziu um estudo onde foram determinadas as elasticidades- 
renda da demanda para vários grupos de alimento, entre os quais, carnes e pescados. Os dados utilizados, obtidos através do ENDEF (Estudo Nacional de Despesa Familiar realizado pelo Instituto Brasileiro de Geografia e Es tatística - IBGE, no período de agosto de 1974 a agosto de 1975), foram dis tribuídos em três grandes classes de despesa. Para a ārea metropolitana e urbana não metropolitana do Estado, as classes consideradas foram: de $\operatorname{Cr} \$ 9.000,00$, ou menos, a $\operatorname{Cr} \$ 22.299,00$, de $\operatorname{Cr} \$ 22.600$ a $\operatorname{Cr} \$ 45.199,00$ e de $\operatorname{Cr} \$ 45,200,00$ a $\operatorname{Cr} \$ 134.799,00$ ou mais. Para a zona rural as classes consideradas foram: $\operatorname{Cr} \$ 4.500,00$, ou menos, a $\operatorname{Cr} \$ 11.299,00$, de $\operatorname{Cr} \$ 11.300,00$ a $\operatorname{Cr} \$ 22.359,00$ e de $\operatorname{Cr} \$ 22.600,00$ a $\operatorname{Cr} \$ 31.599,00$ ou mais. Os cálculos pa ra obtenção das elasticidades-renda foram feitos com base em dois tipos de relação funcional: log-inversa e poligonal bi-logarítmica. As elasticidades obtidas foram:

Log-inversa

Estado de São Paulo

Ārea Metropolittana

Ārea não Metropolitana

Ārea rural

$\begin{array}{lll}1,00 & 0,42 & 0,12 \\ 1,02 & 0,48 & 0,13 \\ 1,02 & 0,43 & 0,15 \\ 1,49 & 0,68 & 0,21\end{array}$

Poligona1

Estado de São Paulo

Ārea Metropolitana

Ārea não Metropolitana

Ārea rural
1,13

1,22

1,11

1,57
0,42

0,46

0,46

0,97
0,20

0,19

0,28

0,44 
Essa literatura consultada, embora bastante rica em informações que pautaram a especificação do modelo a ser utilizado no presente trabalho, trata da modelagem da demanda de carne bovina em diferentes regiões do Brasil, não podendo seus resultados serem extrapolados para o mer cado brasileiro como um todo, servindo apenas como parâmetros de balisamento para estudos que tratem do assunto neste contexto geral.

Outro aspecto a ser considerado é que alguns trabalhos, embora específicos para o mercado brasileiro como um todo, referem-se a períodos que não abrangem anos recentes, onde ocorreram significativas trans formações no mercado de carnes.

Assim, LOBATO (1975) analisou a estrutura do mercado brasileiro de carne bovina e suína, a partir de sērie temporal correspondente ao período 1946-70. As relações de mercado, oferta e demanda, foram estimadas, simultaneamente, pelo método de mínimos quadrados de dois estägios. As equações foram ajustadas com todas as variáveis expressas nos logaritmos decimais dos valores observados, exceto a variável tendência que foi expressa nos números naturais. Os resultados encontrados para a demanda de carne bovina foram: elasticidade-preço direta de curto prazo igual a $-0,94$, elasticidade-preço direta de longo prazo igual a $-1,52$, elas ticidade cruzada com preço de carne suína, de curto e longo prazos iguais a 1,22 e 1,97 respectivamente, e elasticidades-renda iguais a 1,27 e 2,05 de curto e longo prazos, respectivamente.

SIMÕES (1980), utilizando dados de corte seccional extraí dos do ENDEF para o Brasil, ajustou, pelo método de mínimos quadrados ordinārios, equações que fornecem parāmetros para o Sistema Linear Expandido 
de Dispêndio - ELES $^{5}$, vis ando estimar elasticidades-preço e elasticidadesrenda da demanda de värios grupos de alimentos. Para "carnes e pescado" os resultados encontrados foram: $-0,435$ e 0,428 para elasticidade-preço e renda, respectivamente.

LOBATO (1982) analisou, com dados anuais do período 196081, o sistema de demanda de carnes no Brasil. Equações de preço-consumo foram estimadas, simultaneamente, pelo método de mínimos quadrados de dois estágios, com as variāveis expressas nos logaritmos decimais dos valores observados. Os resultados encontrados para carne bovina foram: $-0,66 \mathrm{pa}-$ ra flexibilidade-preço direta e 0,53 para a flexibilidade-renda.

o único trabalho encontrado para o período, com abrangência de anos recentes e para o mercado brasileiro é o de FERNANDES (1988) que, com o objetivo de analisar as consequências econômicas advindas da implantação de políticas de incentivo à demanda e oferta de carnes no mercado brasileiro, estimou, com dados do período 1960-85 (publicados pelo IBGE) as elasticidades preço e renda para a carne bovina, suĩna e de aves. Utilizando uma função de demanda fundamentada no Sistema Diferencial Logarítmico (modelo de Rotterdam) ajustada pelo método de mínimos quadrados ordinários, encontrou,para a carne bovina, elasticidade renda igual a 1,05, elasticidade-preço direta igual a-0,29 e elasticidades cruzadas com preço de suỉno e frango iguais a 0,34 e 0,84 , respectivamente.

50 sistema linear de dispêndio permite redução dos parâmetros a sèrem estimados pela sistema completo de equaçôes de $n^{2}+n$ para $2 n$. Ver BARROS (1987) p.209. 
0 modelo empregado por FERNANDES (1988) não possibilitou a determinação das elasticidades de longo prazo e utiliza, como o dos outros autores citados, uma função de demanda com abordagem setorial, onde não se considera a influência de todos os preços de bens e serviços normalmente consumidos, conforme propõe a Teoria da Utilidade. Nesse aspecto, tornase importante a aplicação de modelos que apresentem um maior grau de compa tibilidade com a teoria, como aqueles integracionistas (consideram a inter-relação de todos os bens e serviços) que são discutidos no capítulo 3.1. Esses modelos integracionistas têm sido utilizados em estudos de demanda de alimentos, todavia, não para o mercado brasileíro.

Para os Estados Unidos da América, GEORGE \& KING, (1971), utilizando um modelo integracionista baseado no conceito de separabilidade homogénea da função de utilidade, obtiveram com dados do período 195565 as elasticidades-preço diretas e cruzadas e elasticidade renda para os alimentos consumidos naquele país. As elasticidades cruzadas para bens pertencentes a grupos diferentes foram obtidas atravēs de relações estabelecidas sob a pressuposição de separabilidade cardinal da função de utilidade, conforme modelo de Frisch. Especificamente para a carne bovina en contraram os valores de $-0,644$ para a elasticidade direta, 0,083 para a elasticidade cruzada com preço de suíno, 0,068 para a elasticidade cruzada com preço de frango e 0,28 para a elasticidade renda.

HEIEN (1982), testando estatisticamente o modelo que desenvolveu sob a pressuposição de separabilidade aditiva da função de utilidade, ajustou, pelo método de mínimos quadrados não lineares em três estágios, funções de demanda para 16 produtos alimentícios. Utilizou dados 
anuais do período 1947-79, referentes ao mercado norte-americano. Para a carne bovina as elasticidades encontradas foram: elasticidade-preço direta igual a $-0,956$, elasticidade-renda igual a 1,270 e elasticidades-cruzadas com preço de suíno e frango iguais a 0,030 e 0,012 , respectivamente.

Dessa forma, apesar da vasta literatura existente sobre demanda de carne bovina, pretende-se através de um modelo integracionista, que tem maior consistência teórica, incorporar à anālise de demanda desse produto, a nível de Brasil, dados recentes sobre renda dos consumidores e sobre o comportamento de mercado do grupo de carnes, que reflitam suas mudanças dos $\bar{u} 1$ timos anos. A atualização constante dos parâmetros dos modelos utilizados para o estudo do mercado de carne bovina se faz necessária no sentido de minimizar suas distorções e tornar as previsões mais seguras. 
2. OBJETIVOS

0 presente estudo tem por objetivo a obtenção de parâmetros da função de demanda de carne bovina para o mercado brasileiro, que . permitam prever variações no seu consumo, resultantes das alterações no seu preço, na renda e nos preços de outros produtos do grupo de alimentos proteicos.

De maneira mais específica, o objetivo deste trabalho ē estimar:

a) elasticidade-preço da demanda de carne bovina, a curto e longo prazos;

b) elasticidades-cruzadas da demanda de carne bovina, a cur to e longo prazos;

c) elasticidade-renda da demanda de carne bovina, a curto e longo prazos. 
o curto prazo pode ser definido como o período de tempo das observações, considerado no presente estudo como um ano. 0 longo prazo apresenta-se como o espaço de tempo necessário para o consumidor se ajus tar ao nível da demanda desejada, após uma mudança no preço ou na renda, pressupondo-se todas as outras coisas constantes, durante o período de ajus tamento. 
3. METODOLOGIA

\subsection{Modelos Integracionistas}

A teoria neo-clássica estabelece que um indivíduo procura maximizar a utilidade derivada do consumo de bens e serviços sujeito a sua restrição orçamentária. Desse modo, a determinação do ponto de ótimo do consumidor $\bar{e}$ um problema de máximo condicionado.

A solução desse problema de maximização resulta em um sistema de equações de demanda da forma geral:

$$
Q_{i}=J_{i}\left(P_{i}, P_{j}, \ldots, P_{n}, Y\right)
$$

onde o consumo "per-capita" de um bem $\left(Q_{i}\right)$ depende de seu preço unitário $\left(P_{i}\right)$, dos preços unitários de todos os demais bens $\left(P_{j}, \ldots, P_{n}\right)$ e da renda "per-capita" (¥).

Uma vez que na anālise empírica deve-se considerar a demanda de todos os bens simultaneamente, tem-se, dado $n$ bens, um total de $n(n+1)$ elasticidades a serem estimadas, sendo $n^{2}$ elasticidades-preço e n elasticidades renda. 
Na estimação da demanda através desse sistema geral, é supos to que certas restrições teóricas, relacionadas ao comportamento do consumidor e à natureza da função de utilidade, sejam satisfeitas. Essas res trições se referem à condição de homogeneidade, simetria (Slutsky) e às restrições de Cournot e Enge ${ }^{6}$.

As restrições citadas, impostas ao sistema completo de equa ções, reduzem o número de parâmetros a serem estimados para $1 / 2\left(n^{2}+n-2\right)$ uma vez que permitem a estimação de certas elasticidades indiretamente ${ }^{7}$. Todavia, essa redução não é considerável e o problema representado pelo alto nümero de parâmetros a estimar continua a existir, tornando inviāvel a utilização desse sistema geral, em decorrência do limitado número de observações existentes (problemas de graus de liberdade). Para contornar essa dificuldade é necessária a adoção de suposiçōes adicionais que deem respaldo teórico ao estabelecimento de modelos para a especificação e estimação de uma equação de demanda para um dado produto.

6 Condição de homogeneidade

$$
e_{i 1}+e_{i 2}+\ldots+e_{i n}+e_{i y}=0 \quad(i=1,2, \ldots, n)
$$

Simetria

$e_{i j}=w_{i j} e_{j i}-w_{j}\left(e_{i j}-e_{j y}\right)$

$$
(i, j=1,2, \ldots, n)
$$

Agregação de Cournot

$$
w_{1} e_{1 j}+w_{2} e_{2 j}+\ldots+w_{n} e_{n j}=-w_{j} \quad(j=1,2, \ldots, n)
$$

Agregação de Engel

$w_{1} e_{1 y}+w_{2} e_{2 y}+\ldots, w_{n} e_{n y}=1$

Ver HENDERSON \& QUANDT (1971) p.31-39 para uma discussão mais detalhada.

7 Ver GEORGE \& KING (1971), p. 21 
Além da abordagem setorial, onde uma simples equação é formulada para estimar as elasticidades diretas e outras poucas cruzadas, pres supondo-se que os efeitos de outras variáveis sejam nulos, duas abordagens diferentes têm sido propostas: $1^{\underline{a}}$ ) as mercadorias são agrupadas (teo ria das mercadorias compostas) e a função de demanda para um dado produto é estimada com base no estabelecimento de números índices; $2 \stackrel{a}{\text { ) }}$ a demanda para bens individuais é estimada, fundamentada no conceito de separabilidade da função de utilidade ${ }^{8}$. Essas duas abordagens são ditas integracionistas

Na primeira abordagem, para o estabelecimento de números Indices, é necessāria a suposição bastante forte de constância nos preços relativos ou nas quantidades relativas consumidas das mercadorias de um mesmo grupo ${ }^{9}$.

Para DEATON \& MULLBAUER (1980), a utilidade dessa teoria, em constituir grupos de mercadorias para anālise empírica, e e $1 i-$ mitada. Numa economia onde flutuações consideráveis nos preços relati vos são esperados, seria possível constituir um número relativamente peque no de agregados. Também o consumo em proporçôes fixas é uma pressuposição pouco real. Mais plausivel parece ser a segunda abordagem, que se baseia no conceito de separabilidade da função de utilidade.

8 Ver GREEN (1971), p.151-165.

9 Se houver $n$ mercadorias $e$ os preços relativos das mercadorias $x_{2}, \ldots, x_{n}$ não variarem, pode-se conduzir a anālise empírica como se houvessem apenas 2 mercadorias $x_{1}$ e $x_{c}$. A mercadoria $x_{c}$ seria uma mercadoria composta, cuja quantidade seria definida como o dispêndio total feito em relação as mercadorias $x_{2}, \ldots, x_{n}$, dividido pelo preço de algum desses bens. Além disso, se um grupo de bens tem a propriedade de que eles são sempre consumidos em proporçôes fixas, por exemplo $x_{1}: x_{2}: x_{3}=2: 3: 1$, pode-se definir uma nova mercadoria como uma cesta $\left(x_{1}, x_{2}, x_{3}\right)=(2,3,1)$ e seu preço por unidade como $2 p_{1}+3 p_{2}+1 p_{3}$. 
o conceito de separabilidade apoia-se na idéia de que os elementos do conjunto de bens e serviços existentes podem ser divididos em diferentes grupos, tais como: vestuário, alimentação, lazer, etc.. No processo de alocação de renda, uma primeira decisão é feita de modo que a renda total do consumidor é repartida entre esses subgrupos e numa segunda decisão a renda destinada a cada um desses subgrupos é alocada entre os bens individuais que fazem parte dele. Cada fração da renda é então gasta otimamente entre as mercadorias de cada subgrupo, sem nenhuma referência adicional às despesas específicas com as mercadorias de outros subgrupos. A renda e os preços de outros bens fora da categoria em análise influenciam a demanda individual somente através de seus efeitos sobre o dispêndio com aquela categoria de bens 10

0 conceito de separabilidade pode ser representado pela seguinte função de utilidade:

$$
\mathrm{U}=\mathrm{U}\left[\mathrm{U}^{\mathrm{A}}\left(\mathrm{q}_{\mathrm{al}}, \ldots, \mathrm{q}_{\mathrm{a} \alpha}\right), \mathrm{U}^{\mathrm{B}}\left(\mathrm{q}_{\mathrm{bl}}, \ldots, \mathrm{q}_{\mathrm{b} \beta}\right), \ldots, \mathrm{v}^{\mathrm{M}}\left(\mathrm{q}_{\mathrm{ml}}, \ldots, \mathrm{q}_{\mathrm{m} \mu}\right)\right],
$$

onde as quantidades $q_{a}$ especificam $U^{A}, q_{b}$ especificam $U^{B}$ e $q_{m}$ especificam $U^{M}$ e $U^{A}, U^{B}$ e $U^{M}$ especificam $U$.

Esquematicamente, para dois grupos, o conceito de separabilidade pode ser representado pelo diagrama:

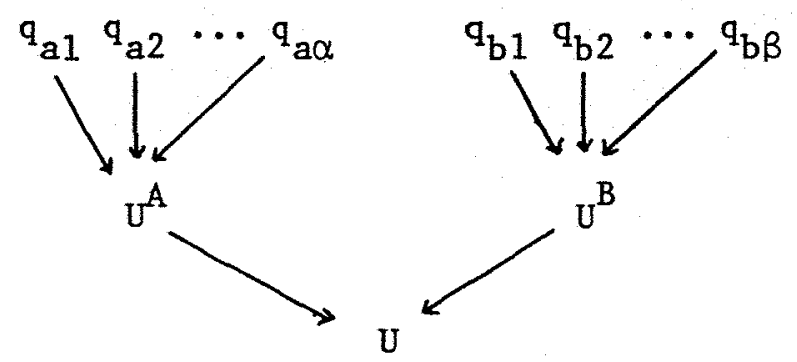

10. STROTZ (1959). 
GREEN (1971) define quatro tipos de separabilidade:

1) Separabilidade Fraca = quando a taxa marginal de substituição entre dois bens de um mesmo grupo é independente da quantidade consumida de outro bem não pertencente a esse grupo, ou seja:

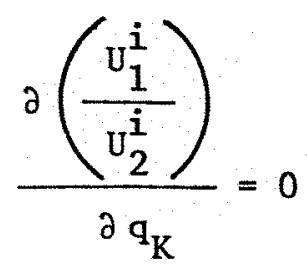

para todo bem do grupo $i$ e $k \notin$ ao grupo $i$, onde $v_{1}^{i} \bar{e}$ a utilidade marginal do consumo do bem 1 do grupo $i, U_{2}^{i} \bar{e}$ a utilidade marginal do consumo do bem 2 do grupo $i$, e $q_{K} \bar{e}$ a quantidade consumida do bem $k$.

Para GOLDMAN \& UZAWA (1964), a função de utilidade é do tipo fracamente separāvel se ela for da forma geral:

$$
\mathrm{U}\left(\mathrm{q}_{1}, \ldots, \mathrm{q}_{\mathrm{n}}\right)=\mathrm{F}\left[\mathrm{U}^{1}\left(\mathrm{q}^{1}\right), \mathrm{u}^{2}\left(\mathrm{q}^{2}\right), \ldots, \mathrm{u}^{5}\left(\mathrm{q}^{5}\right)\right]
$$

onde

$$
u^{i}\left(q^{i}\right)=u^{i}\left(q_{1}^{i}, q_{2}^{i}, q_{3}^{i}, \ldots, q_{n}^{i}\right)
$$

$\operatorname{com} \quad i=\{1,2,3, \ldots, 5\}$

2) Separabilidade de Pearce: quando a taxa marginal de substituição entre dois bens de um mesmo grupo é independente da quantidade consumida de qualquer outro bem do sistema, ou seja:

$$
\frac{\partial\left(\frac{U_{i}}{U_{j}}\right)}{\partial q_{K}}=0
$$

para $i$ e $j \in$ ao grupo g e $k \neq i, j$. 
o conceito de separabilidade de Pearce é aplicado para funções do tipo:

$$
\begin{aligned}
U\left(q_{1}, \ldots, q_{n}\right)= & U\left\{U^{1}\left[f_{1}^{1}\left(q_{1}^{1}\right)+\ldots+\operatorname{fn}_{1}^{1}\left(q_{1}^{1}\right)\right]+\ldots+\right. \\
& \left.+U^{s}\left[f_{1}^{s}\left(q_{1}^{s}\right)+\ldots+\operatorname{fn}_{s}^{s}\left(q_{s}^{s}\right)\right]\right\}
\end{aligned}
$$

3. Separabilidade Forte ou Aditiva: quando a taxa marginal de substituição entre dois bens de dois grupos distintos é independente da quantidade consumida de qualquer outro bem, de qualquer outro grupo. Nesse contexto:

$$
\frac{\partial\left(\frac{u^{i}}{U_{j}}\right)}{\partial q_{K}}=0
$$

para todo $i \in$ grupo $g, j \in$ grupo $m$ e $k \in$ grupo $s$.

Uma função è do tipo fortemente separável se ela for da for ma aditiva entre grupos, ou seja:

$$
\left.U\left(q_{1}, \ldots, q_{n}\right)=F\left[u^{1}\left(q^{1}\right)+U^{2}\left(q^{2}\right)+\ldots+u^{s}\right)\right]
$$

onde

$$
u^{i}\left(q^{i}\right)=u^{i}\left(q_{1}^{i}, q_{2}^{i}, q_{3}^{i}, \ldots, q_{n}^{i}\right)
$$

Quando todos os grupos têm somente um elemento, tem-se a completa aditividade da função de utilidade. Nesse caso, a utilidade derivada do consumo de um bem independe da quantidade consumida de qualquer outro bem, o que è denominado "independência de vontade". 
4. Separabilidade Homogênea: envolve separabilidade fraca e se aplica a funções cujas superfícies de indiferença que relacionam bens de um mesmo grupo são homotéticas com respeito à origem. Isso implica em elasticidade renda unitária, para cada bem de um grupo, com relação ao dis pêndio nele realizado ${ }^{11}$.

Os tipos enunciados de separabilidade não são mutuamente ex clusivos, Separabilidade de Pearce inclue separabilidade fraca e aditiva, enquanto que separabilidade homogênea e aditiva incluem separabilidade fraca ${ }^{12}$.

Pressuposições sobre os diversos tipos de separabilidade têm permitido a formulação de modelos para a estimação de parâmetros da função de demanda, viāveis sob o ponto de vista estatístico e com facilidade de operacionalização.

STROTZ (1959), desenvolve um modelo baseado no conceito de separabilidade aditiva, obtendo funçōes de demanda da forma:

$$
q_{j}^{\prime}=\sum_{j \in J} \alpha j^{\prime} j P_{j}+\beta{ }_{j}^{\prime}\left(P_{I}+P_{K}+\ldots+P_{N}+Y\right)+\alpha j_{0}^{\prime}
$$

onde a quantidade de um determinado bem é dependente de seu preço, dos pre ços dos outros bens do grupo, dos índices de preço dos grupos dos outros

11 As funções de utilidade são ditas homotéticas quando as curvas de indiferença que relacionam bens de um mesmo grupo são versão ampliada ou reduzida uma das outras, de modo que todo raio que parte da origem atin ge-as em pontos cujas tangentes tềm a mesma inclinação. Devido a essā propriedade de inclinação constante, as curvas de renda consumo, dados por aumentos de renda, com preços fixos, são linhas retas que partem da origem. Dessa forma a composição do dispêndio no grupo é independente do nivel de utilidade e do total dispendido. Ver DEATON \& MUELLBAUER (1980), p.143-47.

12 Ver GREEN (1971), p.151-56 e GEORGE \& KING (1971), p. 27. 
bens e da renda. 0 autor determina o coeficiente de relação inter-grupos co mo sendo $\alpha j^{\prime} i^{\prime}=\beta j^{\prime} w_{i}^{\prime}$, onde $\beta j^{\prime} \bar{e}$ o coeficiente da variável renda do bem $j^{\prime}$ e $w_{i}^{\prime}$ é a proporção do dispêndio no bem i' em relação ao dispêndio total do grupo $i$.

GREEN (1971) propõe um modelo de orçamentação em dois estāgios baseado no conceito de separabilidade homogênea, obtendo duas formas de função de demanda, onde os argumentos são: numa das formas, os preços individuais dos bens do grupo particular e a renda despendida no grupo; na outra forma, os preços individuais dos bens do grupo, os índices de preço de todos os grupos e a renda global. Esse modelo não permite a obtenção de elasticidades cruzadas para bens de diferentes grupos ${ }^{13}$.

HEIEN (1982), sob a pressuposição de separabilidade aditiva, utilizando uma função de utilidade do tipo "S-branch" derivada da função CES, desenvolve a seguinte função de demanda:

$$
\begin{aligned}
\ln q_{s i} & =a_{s i} \theta_{s i}+b_{s i} \theta_{s i} \ln P+c_{s i} \theta_{s i} \ln P_{s}+ \\
& +d_{s i} \theta_{s i} \ln P_{s i}+1_{s i} \theta_{s i} \ln m
\end{aligned}
$$

onde

$\mathrm{q}_{s i}=$ quantidade do produto, $\mathrm{P}=$ indice de preço de "todos os bens",

$P_{S}=$ Índice de preço do grupo do bem cuja demanda está sendo estimada, $P_{s i}=0$ preço do bem e $m=$ renda.

0 modelo desenvolvido por HEIEN, as sim como o de STROTZ, per mite a obtenção de elasticidades para bens de grupos diferentes.

13 A pressuposição de funções de preferências homotéticas é necessāria para o estabelecimento dos indices utilizados no primeiro estágio de orçamentação. 
FRISCH (1959), embora não proponha especificamente um modelo para estimação de funções de demanda, desenvolve, sob a pressuposição de "independência de vontade", uma matriz de coeficientes de demanda. Partindo de estimativas anteriores de elasticidade direta e renda de um deter minado bem e da parcela de renda gasta nesse bem, determina o valor da fle xibilidade da moeda $(\phi)$ e, a partir daí, as elasticidades diretas e cruzadas para todos os bens para os quais se conheça a elasticidade renda e a parcela de renda nele despendida ${ }^{14}$.

\subsection{O Modelo Utilizado}

3.2.1. Orçamentação em dois estágios

Este estudo utiliza o modelo de orçamentação em dois estágios baseado no conceito de separabilidade homogênea da função de utilidade. 0 modelo, descrito por GREEN (1971), consiste em:

\section{Primeiro Estāgio}

Dada a função de utilidade:

$$
\mathrm{U}=\mathrm{U}\left[\mathrm{U}^{\mathrm{A}}\left(\mathrm{q}_{\mathrm{al}}, \ldots, \mathrm{q}_{\mathrm{a} \alpha}\right), \mathrm{U}^{\mathrm{B}}\left(\mathrm{q}_{\mathrm{bl}}, \ldots, \mathrm{q}_{\mathrm{b} \beta}\right), \ldots \mathrm{U}^{\mathrm{M}}\left(\mathrm{q}_{\mathrm{ml}}, \ldots, \mathrm{q}_{\mathrm{m} \mu}\right)\right]
$$

define-se um Índice de quantidade para cada grupo, que é função das quantidades dos bens do grupo:

$$
q^{A}=q^{A}\left(q_{a 1}, \ldots, q_{a \alpha}\right), q^{B}=q^{B}\left(q_{b 1}, \ldots, q_{b \beta}\right), \ldots q^{M}=q^{M}\left(q_{m 1}, \ldots, q_{m \mu}\right)
$$

$$
\begin{array}{r}
14 n_{i j}=-w_{j} n_{i y}\left(1+\frac{n_{j y}}{\phi}\right. \\
n_{i i}=-n_{i y}\left[w_{i}-\frac{\left(1-w_{i} n_{i y}\right)}{\phi}\right] \\
\text { onde: } \quad \phi=\frac{n_{i y}\left(1-w_{i} n_{i y}\right)}{n_{i i}+w_{i} n_{i y}}
\end{array}
$$


e insere-se seus valores numa função de utilidade:

$$
U^{*}=f\left(q^{A}, q^{B}, \ldots, q^{M}\right)
$$

Da mesma forma pode-se definir indice de preços:

$$
p^{A}=p^{A}\left(p_{a 1}, \ldots, p_{a \alpha}\right), p^{B}=p^{B}\left(p_{b 1}, \ldots, p_{b \beta}\right), \ldots p^{M}=p^{M}\left(p_{m 1}, \ldots, p_{m \mu}\right)
$$

e encontrar valores de $q^{A}, q^{B}, \ldots q^{M}$, que maximizam $U^{*}$, sujeitos a restrição orçamentäria:

$$
p^{A} q^{A}+p^{B} q^{B}+\ldots+q^{M} p^{M}=Y
$$

Desse processo de maximização decorrem $S$ valores de $q^{*}$.

Dados os índices de preços, tem-se as rendas $\mathrm{Y}_{i}$ a serem despendidas em cada grupo, com i variando de A até M.

\section{Segundo Estãgio}

No segundo estágio, $U^{i}=u^{i}\left(q_{i 1}, q_{i 2}, \ldots, q_{i \gamma}\right) \bar{e}$ maximizado para cada i, sujeito a:

$$
\Sigma \mathrm{p}_{i 1} \cdot \mathrm{q}_{\mathrm{il}}=\mathrm{Y}_{\mathrm{i}}
$$

Como resultado tem-se, por exemplo, para o bem 1 do grupo a:

$$
q_{a 1}=q_{a 1}\left(p_{a 1}, p_{a 2}, \ldots, p_{a \alpha}, \mathrm{P}_{i}\right)
$$

que pode ser reescrito na forma:

$$
q_{a 1}=q_{a 1}\left(p_{a 1}, p_{a 2}, \ldots, p_{a \alpha}, p^{A}, p^{B}, \ldots p^{M}, \quad\right)
$$


tendo-se em conta que:

$$
M_{i}=M_{i}\left(p^{A}, p^{B}, \ldots, p^{M}, Y\right)
$$

\subsubsection{Modelo de Defasagem Distribuỉda}

Para a obtenção das elasticidades de longo prazo foi utilizado o modelo de defasagem distribuída.

A teoria estática pressupõe que o ajustamento do consumo de um bem, após as mudanças no seu preço e na renda do consumidor, é instantânea. No entanțo, em decorrência de fatores psicológicos, tecnológicos e institucionais, existe uma certa rigidez no ajuste da demanda, de modo que uma mudança no preço ou na renda produz efeito sobre o consumo de um bem somente após um certo espaço de tempo, chamado de defasagem. Es se efeito, quando ocorre, não acontece num số período, mas é distribuído por uma sequência de períodos de tempo.

0 mētodo, baseado na existência de defasagem distribuída, além de permitir a obtenção de elasticidades de longo prazo, possibilita a determinação do período necessário para o ajustamento, ou melhor, o tem po necessário para que o consumidor, após uma variação de preço e/ou renda, atinja o nível de consumo desejado, com todas as outras coisas permanecendo constantes.

A trajetória da demanda para o seu equilíbrio de longo pra zo é assintótica, de modo que o equilíbrio só será atingido formalmente no infinito. E possível, no entanto, calcular o período de tempo requerido para que a demanda efetiva se iguale a uma proporção " $\alpha$ " da demanda 
de longo prazo.

0 modelo sugerido para representar a situação da defasagem distribuĩda teria a seguinte forma ${ }^{15}$ :

$$
\begin{aligned}
& Q_{t}-Q_{t-1}=\delta\left(Q_{t}^{*}-Q_{t-1}\right) \quad 0<\delta<1 \\
& Q_{t}^{*}=a+b P_{t}+c Y_{t}
\end{aligned}
$$

onde

$$
\begin{aligned}
& Q_{t}=\text { consumo "per-capita" } \\
& P_{t}=\text { preço unitärio do produto } \\
& Q_{t}^{*}=\text { consumo "per-capita" desejado } \\
& \delta \quad=\text { coeficiente de ajustamento } \\
& t \quad=\text { período } \\
& Y_{t} \quad=\text { renda "per-capita" }
\end{aligned}
$$

A equação (I) descreve o processo de ajustamento parcial da demanda, desenvolvido por NERLOVE (1958). A hipótese de rigidez no ajuste da demanda sugere que a taxa de ajuste de consumo entre dois períodos $\left(Q_{t}-Q_{t-1}\right)$ é proporcional a diferença entre o consumo observado em $t-1$ e o consumo de equilíbrio de longo prazo. 0 coeficiente $\delta$ dá a proporção da mudança de longo prazo que de fato é realizada em um período. A equação(II) é considerada uma função de demanda de longo prazo, que sendo substituída em I resulta, apōs alguns ajustes, em:

15 Ver BARROS (1987), p. 222. 


$$
Q_{t}=\delta_{a}+\delta_{b} P_{t}+\delta_{c} Y_{t}+(1-\delta) Q_{t-1}
$$

que pode ser reescrita na forma:

$$
Q_{T}=\pi_{0}+\pi_{1} P_{t}+\pi_{2} Y_{t}+\pi_{3} Q_{t-1}
$$

onde

$$
\begin{aligned}
& \pi_{0}=\delta_{a} \\
& \pi_{1}=\delta_{b} \\
& \pi_{2}=\delta_{a} \\
& \pi_{3}=1-\delta
\end{aligned}
$$

Esse modelo supõe implicitamente que os coeficientes de ajuste de preços e renda são idênticos $(\delta)$.

o cálculo desse coeficiente de ajustamento é feito subtraindo-se o coeficiente da variāvel $Q_{t-1}$ da unidade.

As elasticidades de longo prazo são definidas como:

$$
\begin{aligned}
& \mathrm{EL}_{\mathrm{p}}=\frac{\mathrm{EC}_{\mathrm{p}}}{1-\pi_{3}}=\frac{\mathrm{EC}_{\mathrm{p}}}{\delta} \\
& E L_{\mathrm{p}}=\frac{E C_{\mathrm{Y}}}{1-\pi_{3}}=\frac{E C_{\mathrm{Y}}}{\delta}
\end{aligned}
$$

Esse método pode ser facilmente estendido para cobrir casos em que os preços dos produtos substitutos ou complementares estão incluídos na função de demanda de longo prazo.

A determinação do intervalo de tempo necessārio para atingir o nível de consumo de longo prazo é dado por: 


$$
t=\frac{\ln (1-\alpha)}{\ln (1-\delta)}
$$

onde

$$
\begin{aligned}
& t=\text { tempo } \\
& \delta=\text { coeficiente de ajustamento } \\
& \alpha=\text { proporção do ajuste de longo prazo desejado }
\end{aligned}
$$

A inclusão da quantidade retardada numa equação de demanda é portanto uma hipótese testável. Se $\delta$ for igual à unidade, o valor do coeficiente da variāvel retardada é zero, implicando que o ajustamento do consumidor às variações no preço e/ou na renda é instantâneo, como pressupõe a teoria estātica. Se o coeficiente da variāvel retardada for significativo estatisticamente, supõe-se que os dados sustentam a hipötese de que o ajustamento total a uma variação nos preços e renda não ocorre num só perĩodo de tempo.

\subsubsection{Teste de Causalidade}

Os analistas de demanda reconhecem que para alguns produtos da agropecuária a demanda é predeterminada. Como resultado, variações nas quantidades demandadas resultam em variações nos preços. Quando isso ocorre, considerações estatísticas sugerem alguma forma de função $\mathrm{p}$-dependente.

Visando a correta especificação da função de demanda, necessārio se faz, portanto, a identificação do sentido da causalidade, ou seja, a identificação de qual entre duas variáveis correlacionadas deve ser considerada a dependente. 
As possiveis relações de causalidade entre duas variáveis $Q_{a}$ e $P_{a}$ são:

a) $Q_{a}$ causa $P_{a}$

b) $P_{a}$ causa $Q_{a}$

c) $Q_{a}$ e $P_{a}$ são mutuamente relacionadas quanto a direção da causalidade $\left(Q_{a} \leftrightarrow P_{a}\right)$ e,

d) ausência de causalidade entre as duas variāveis.

Para a verificação do sentido de causalidade foi utilizado o teste proposto por SIMS (1972) que postula: se, e somente se, o sentido de causalidade for unicamente dos valores presentes e passados de uma série de variáveis exógenas para uma dada variável endógena, tem-se, numa regressão de variável endógena, com valores passados, correntes e fu turos das variáveis exógenas, resultados nulos para os coeficientes futuros das variáveis exógenas.

O teste de causalidade proposto por SIMS requer a realiza ção de uma filtragem das séries de variāveis quando na regressão for detectada autocorrelação entre os resíduos ${ }^{16}$. Isso se faz necessārio porque os procedimentos econométricos a serem utilizados na determinação do sentido de causalidade envolvem a realização de testes $F$, que requerem au sência de vieses associados a correlação serial entre os erros ${ }^{17}$.

\footnotetext{
16 Ver BISHOP, 1979.

17 Ver STMS, 1972.
} 
Para a realização do teste de causalidade o procedimento estatístico adotado consistiu em estimar funções da seguinte forma:

$$
\begin{aligned}
& q a_{t}=a_{1} p_{t}+\sum_{i=1}^{4} a_{2} p a_{t+i}+\sum_{K=1}^{8} a_{3 k} p a_{t-k}+a_{4} T+e_{1 t} \\
& p a_{t}=b_{1} q a_{t}+\sum_{i=1}^{4} b_{2} q a_{t+i}+\sum_{K=1}^{8} b_{3 k} q a_{t-K}+b_{4} T+e_{2 t}
\end{aligned}
$$

onde

$$
\begin{aligned}
& \mathrm{qa}=\text { quantidade consumida do produto ("per-capita") } \\
& \mathrm{pa}=\text { preço real do produto } \\
& \mathrm{T}=\text { variāvel tendência } \\
& \mathrm{e}_{1 t}, \mathrm{e}_{2 t}=\text { erros aleatórios }
\end{aligned}
$$

As variáveis foram mantidas com 8 (oito) defasagens e 4 (quatro) valores futuros, baseando-se em metodologia sugerida por BISHOP (1979) e utilizada por TEIXEIRA (1982), BURNQUIST (1986), MARTINES Fo (1988) e outros .

A existência de correlação serial entre os erros foi acompanhada pelo teste de Durbin-Watson (DW) e teste Q.

Para a filtragem das séries utiliza-se a seguinte tëcni$\mathrm{ca}^{18}:$

- obtem-se as estimativas, por mínimos quadrados ordinários (MQO) de por exemplo:

$$
Q_{a}=\sum_{K=-4}^{8} \alpha_{K} p a_{t-K}+e_{t}
$$

18 A filtragem e demais procedimentos econométricos foram realizados atra vés do "software" RATS (DOAN \& LITTERMAN, 1981). 
onde

$$
\begin{aligned}
& \mathrm{Q}_{\mathrm{a}}=\text { quantidade do produto } \\
& \mathrm{P}_{\mathrm{a}}=\text { preço do produto }
\end{aligned}
$$

e calcula-se os resíduos $\hat{e}_{1}, \hat{e}_{2}, \ldots, \hat{e}_{n}$, e a partir daí $\hat{\rho}$, que $\bar{e}$ dado por:

$$
\rho=\frac{\sum \hat{e}_{t}-\hat{e}_{t-1}}{\sum \hat{e}_{t-1}^{2}} \quad(t=2, \ldots, n)
$$

- posteriormente constrōi-se novas variāveis:

$$
Q_{a}^{*}=\left(Q_{a}-\hat{\rho} Q_{a_{t-1}}\right) \text { e } P_{a}^{*}=\left(P_{a}-\hat{\rho} P_{a_{t-1}}\right)
$$

- obtēm-se as estimativas, por MQO de:

$$
Q_{a}^{*}=\sum_{K=-4}^{8} \alpha_{K} P_{t-K}^{*}+u_{t} \quad(t=2,3, \ldots, n)
$$

e

$$
u_{t}=e_{t}-\hat{\rho} e_{t-1}
$$

A eliminação da autocorrelação serial entre os erros pode ser avaliada estimando-se $\theta(M Q O)$ na seguinte equação:

$$
u_{t}=\theta\left(u_{t-1}\right)+v_{t}
$$

Se o coeficiente $\theta$ se apresentar não significativo estatisticamente, considerando-se um nível de $5 \%$ de probabilidade, pela utilização do teste " $t$ " - Student, pode-se dizer que os erros não apresentam auto-correlação de primeira ordem e que o p foi eficiente como fiḷtro. Ca so $\rho$ se apresente significativo, realiza-se uma nova filtragem de série $Q_{a_{t}}^{*}+P_{t}^{*}$ 
Após ter-se atenuado a autocorrelação serial entre os erros, atravēs da filtragem da série de variāveis, passa-se ao teste de hipōtese:

I) $a_{21}=a_{22}=a_{23}=a_{24}=0$

II) $b_{21}=b_{22}=b_{23}=b_{24}=0$

Para testar estas hipōteses utilizou-se o procedimento apre sentado por KMENTA (1978), aplicando-se a cada uma das expressões I e II a estatîstica F:

$$
F=\frac{S Q E r-S Q E u) /(q-p)}{S Q E u /(n-q)}
$$

onde

SQEr = Soma dos quadrados dos resíduos da regressão com restrição:

$$
a_{2 i}=0(i=1, \ldots, 4) \text { em } I \text { e } b_{2 i}=0(i=1, \ldots, 4) \text { em II }
$$

$\mathrm{SQEu}=$ Soma dos quadrados dos resíduos da regressão sem restrição

$\mathrm{p}=$ número de parâmetros estimados na regressão sem restrição

$q=$ número de parâmetros estimados na regressão restrita

$\mathrm{n}=$ número total de observações.

Se a hipótese I for rejeitada e a hipōtese II não, tem-se condiçôes necessärias e suficientes para estabelecer-se causalidade de $Q_{a}$ para $P_{a}\left(Q_{a} \rightarrow P_{a}\right)$. o conträrio deve ocorrer quando rejeita-se II e não rejeita-se I. Se as duas hipóteses forem rejeitadas, estabelece-se uma relação bicausal $\left(Q_{a} \rightarrow P_{a}\right)$ e, finalmente, se ambas as hipóteses não forem rejeitadas, conclui-se pela ausência de causalidade entre $Q_{a}$ e $P_{a}$. 
Atravēs dos resultados obtidos no ajuste das funções A e B (com séries de variáveis desprovidas de correlação serial entre os erros) calculou-se os valores de F para o teste de hipótese. Os valores encontrados foram:
I) $F=0,287$
II) $\mathrm{F}=1,430$

Para os dois casos, adotando-se os níveis de significância de 1,5 ou $10 \%$ o valor crítico de F (com 4 e 6 graus de 1iberdade) é sempre maior que o F estimado. Dessa forma, não se rejeita a hipótese de: $a_{21}=a_{22}=a_{23}=a_{24}=0$ em I e $b_{21}=b_{22}=b_{23}=b_{24}=0$ em II

Não tendo sido identificada qualquer relação causal entre as variáveis $Q_{a}$ e $P_{a}$, optou-se por especificar a função de demanda na for ma q-dependente. A dependência preço, embora vista como uma perspectiva estatística, deixa a edificação teórica incompletamente abordada, conduzindo a especificações "ad hoc" e, muitas vezes, a interpretações ambiguas dos resultados. Além do mais, as quantidades que integram as relaçóes de demanda de alimentos estão sujeitas a maiores erros de estimação do que os preços ao varejo ${ }^{19}$.

\subsubsection{Especificação Empírica}

Apōs o estabelecimento das premissas teôricas e consideran do que as condiçôes para uma agregação consistente são satisfeitas ${ }^{20}$, especificou-se o modelo de demanda de carne bovina a ser utilizado na análise empîrica.

19 Ver HEIEN (1982).

20 Ver DEATON \& MUELLBAUER (1980), p. 148. 
A função de demanda foi especificada na forma linear, fundamentada numa função de utilidade do tipo stone-Geary: $u=\sum_{i} B_{i} \log \left(x_{i}-y_{i}\right)$ com $0<\mathrm{B}_{i}<1$ e $\sum_{\mathbf{i}} \mathrm{B}_{\mathbf{i}}=1$. Essa função de utilidade se aplica a estudos de consumo de bens substitutos e normais (elasticidade-renda >0 ${ }^{21}$.

Uma versão do modelo tem a seguinte forma, sem considerar os sinais dos coeficientes:

$$
Q_{c B}=P_{c B}+\pi_{2} P_{c S}+\pi_{3} P_{c F}+\pi{ }_{4} P_{1}+\pi_{5} P_{2}+\pi_{6} P_{3}+\pi_{7} Y_{i}+\pi_{8} Q_{c B t-1}+\pi_{9} T+u
$$

onde:

$Q_{c B}=$ quantidade de carne bovina consumida expressa em quilogramas "per-capita" no ano $t$.

$P_{C B}=$ preço de carne bovina expressa em cruzeiros por quilograma no ano $t$.

$\mathrm{P}_{\mathrm{cS}}=$ preço de carne suína expressa em cruzeiros por quilograma no ano $t$.

$P_{C F}=$ preço de carne de frango expressa em cruzeiros por quilograma no ano $t$.

$Q_{\mathrm{cBt}-1}=$ quantidade de carne bovina consumida no período anterior, expressa em quilograma "per-capita".

$P_{1}=$ Indice de preço do grupo de carnes

$\mathrm{P}_{2}=$ indice de preço de outros alimentos

$\mathrm{P}_{3}=$ Indice de preço de não alimentos

21 Ver PHILIPS (1983), p.122-28. 


$$
\begin{aligned}
& \mathrm{Y}_{\mathrm{t}}=\text { renda "per-capita" expressa em cruzeiros no ano } t \\
& \mathrm{~T}=\text { tendéncia (tempo) } \\
& \mathrm{u}=\text { termo estocástico }
\end{aligned}
$$

Mesmo considerando que o pescado tem, dentro do grupo "carnes consumidas no mercado brasileiro", uma certa representatividade, foi inviāvel a sua inclusão no modelo, dada a não disponibilidade de dados fidedignos de seu preço ao varejo para a série temporal em análise.

Uma vez que a teoria sugere que o preço de todos os produtos de uma categoria devem ser incluídos, a exclusão dos mesmos equivale a imposição de valor zero aos respectivos coeficientes.

Em termos econométricos, o nümero reduzido de observações limita a inclusão de todos os indices de preço dos grupos de bens e serviços. Dessa forma, pressupôs-se que os três grupos de dispêndio são: carnes, outros alimentos e não alimentos.

o fato constatado de que a série de consumo de carne bovina apresenta uma tendência decrescente, que pode ser atribuível, em parte, a deslocamentos sistemáticos de variāveis não incluídas na equação, torna necessäria a inclusão na função de demanda de uma variável $t$.

A variável estocástica (u) representa as perturbações aleatórias do comportamento humano e os possíveis erros de observação e de medida.

No modelo especificado, pressupõe-se que todas as variāveis independentes sejam pré-determinadas, de tal forma que a função seja exatamente identificável. 


\subsection{Testes Estatísticos}

A função de demanda de carne bovina foi ajustada pelo Método dos Mínimos Quadrados. Este método requer que ${ }^{22}$ :

I) a variāvel dependente $\left(Y_{j}\right)$ seja função linear das variāveis independentes $\left(x_{i j}=1, \ldots, k\right)$;

II) os valores das variáveis sejam fixos;

III) $E(u)=0$, onde 0 representa um vetor de zeros;

IV) os erros sejam homocedāsticos, isto $\bar{e}, E(u j)=\sigma^{2}$.

V) os erros sejam não correlacionados entre si, isto $\bar{e}$, $E(u j u h)=0$ para $j \neq h$.

Para a verificação do nîvel de significância da regressão e das estimativas dos parâmetros obtidos foram utilizadas as estatísticas "F" de Snedecor e " $t$ " de Student.

Tanto para "F" quanto para " $t$ " foram considerados os níveis de 1,5 ou $10 \%$ de probabilidade para indicar, respectivamente, a significância da regressão e das estimativas dos parâmetros da equação.

Para a averiguação da existência de correlação serial nos resíduos, utilizou-se o teste Box-Pierce $(Q)^{23}$ que permite a

22 Ver HOFFMANN \& VIEIRA (1983), p.109-110.

23 Teste Q - estatística de Box-Pierce, que é dado por:

$$
Q=n \sum_{k=1}^{k} r_{k}^{2}(\hat{e}) \text { onde: } r_{k}(\hat{e})=\frac{\sum_{t=k+1}^{n} \hat{e}_{t} \hat{e}_{t-k}}{\sum_{t=1}^{n} \hat{e}_{t}^{2}} \text {. A estatistica } Q \text { apresen- }
$$

ta distribuição de Qui-quadrado com $\mathrm{K}$ graus de $\mathrm{I}$ iberdade. 
deteç̧ão de correlação serial de ordem superior a um ${ }^{24}$.

E sabido que o desempenho do método de mínimos quadrados, quando existe autocorrelação nos resĩduos, é bastante sofrível. Conforme a magnitude da autocorrelação constatada, os parâmetros podem ser substan cialmente viesados, conduzindo a inferências imprecisas sobre o comportamento do modelo ${ }^{25}$.

\subsection{Dados}

o ajuste da função de demanda foi feito utilizando-se dados anuais do período 1957-1987.

\section{Preços}

Não havendo disponibilidade de sēries de preço que cubram todo o país, foram utilizados preços da capital de São Paulo como representativos dos preços nacionais. Os dados de preços utilizados são réferentes à média ponderada dos preços coletados em uma amostra representatí va dos estabelecimentos varejistas, pela FIPE - Fundação Instituto de Pes quisas Econômicas/USP. No caso de carne bovina e suína os preços são formados a partir de diferentes cortes, ponderados pela participação do corte no total da carcaça ${ }^{26}$.

24 Ver HOFFMANN \& VIEIRA (1983), p. 272-273.

25 PASTORE (1973), p. 101.

26 Foi adotado como base de ponderação o Sistema Ponderal de Cónversões do estudo realizado por Canto (1988), publicado pelo ITAL - -. Instituto de Tecnologia de Alimentos. 
Transformou-se os preços mensais, tomados em cruzeiros por quilograma, de valores correntes para valores reais de dezembro de 1987 , utilizando-se o Indice Geral de Preços/IGP, como deflator ${ }^{27}$. Foram calculadas, posteriormente, as médias anuais simples desses preços deflacionados.

\section{Consumo de Carne Bovina}

Foi utilizada como representativa do consumo "per-capita" de carne bovina a variāvel disponibilidade "per-capita". Essa variāvel foi determinada através dos dados anuais de produção doméstica mais importação e menos exportação, tendo sido, os resultados, divididos pelas estimativas da população. Os estoques não foram considerados na obtenção desta variāvel por não se dispor de seus valores para toda a série em anālise.

Os dados utilizados na determinação dessa variável foram obtidos atravēs de informações fornecidas pelo IBGE (Anuārio Estatístico) para a produção doméstica e Ministério da Fazenda, CACEX para importação e exportação. Não tendo sido coletados pelo IBGE dados de produção doméstica nos anos $72 / 74$, foram utilizados, para esse período, dados publicados no Boletim Etac Mercados-Carnes. Alguns autores tentaram estimar esses dados ausentes das estatîsticas atravēs de regressões, comparações com dados observados em alguns estados da Federação ou obter estimativas por interpolação dos dados de 1970-71 e 1975-76. Não hä como avaliar a validade desses procedimentos, bem como a fidedignidade dos dados publicados pelo ETAC.

27 Dados do IGP extraídos de CONJUNTURA ECONŌMICA (1971-87). 
0 procedimento adotado para transformação dos valores de exportação e importação de carne bovina industrializada em equivalente de carcaça foi baseado no trabalho de LATTIMORE (1974) que utilizou, como fator de conversão, o valor de 2,5 .

Uma limitação desta metodologia é a questionāvel precisão dos coeficientes de conversão utilizados para carne bovina industrializada, uma vez que existem diferentes tipos de produtos preparados, que deveriam receber, cada um deles, um fator diferente de conversão. Todavia os dados disponíveis não são discriminados ao nîvel de informar o tipo de pre paro de cada produto comercializado.

Não foi utilizado fator de conversão para carne bovina comercializada sem osso, dada a indisponibilidade de especificação (com ou sem osso) nas estatîsticas consultadas, para a maior parte dos anos da série utilizada na anālise.

\section{Renda}

Como "proxy" da variävel renda"per capita" utilizou-se a variāvel PIB (Produto Interno Bruto) "per capita"

Os dados de PIB "per capita" foram deflacionados pelos da dos de IGPs médios (anuais) tomando-se como base o ano de 1987 . 
Indices de Preços

Foram utilizados indices de preços da FIPE, construídos pela metodologia de Divísia ${ }^{28} \mathrm{com}$ a seguinte fórmula:

$$
I_{t-1 . t}=\exp \left[\sum_{i=1}^{n} w_{0}^{i} \cdot \ln \left(\frac{p_{t}^{i}}{p_{t-1}^{i}}\right)\right]
$$

onde:

$$
\begin{aligned}
& w_{o}^{i}=\text { ponderação do item } i \text { na pesquisa base (orçamentos familiares) } \\
& p_{t}^{i}=\text { preço médio do item } i \text { no mês corrente } \\
& p_{t-1}^{i}=\text { preço médio do item } i \text { no mês anterior }
\end{aligned}
$$

Os resultados obtidos mensalmente são encadeados à série tomando-se como base um determinado período.

Atravēs desses indices obtidos pela FIPE ${ }^{29}$ obteve-se os indices aglutinados requeridos no nosso estudo.

Não tendo sido publicados pela FIPE, para todos os anos da série em análise, Indices de preço para o grupo carnes, estes foram construídos utilizando-se a mesma metodologia e bases de ponderação utilizadas por aquela Instituição 30 .

Os îndices de preço foram deflacionados por dados de IGP médios anuais, tomando-se como base o ano de 1987 .

\footnotetext{
28 Ver ENDO \& CARMO, 1985.

29 Ver ENDO \& CARMO, 1985 e Séries Estatísticas / FIPE, 1988. 30 Ver RIZZIERI, 1987.
} 
4. RESULTADOS E DISCUSSÃO

Antes de discutir-se as relações obtidas com o modelo econométrico proposto, capazes de permitir a determinação das elasticidades, pretende-se fazer uma breve anālise da evolução do mercado de carne bovina no período estudado.

4.1. Anālise da Evolução do Mercado de Carne Bovina-Período 1957-87

A anālise do consumo de carne bovina no período de 1957-87 será realizada no sentido de verificar o seu comportamento evolutivo face às variaçóes do seu próprio preço, dos preços das carnes de frango e suína e da renda dos consumidores. Essa anālise, a ser feita através do estabelecimento de relaçóes entre cada uma das variáveis citadas e o consumo de carne bovina, tem como objetivo apenas fornecer algum subsídio para a iden tificação de possîveis causas das variações ocorridas no consumo desse ali mento no decorrer do período.

As Figuras 1, 2, 3 e 4 apresentam as relações de consumo de carne bovina e as variáveis preço (de carne bovina, suína e de frango) e 


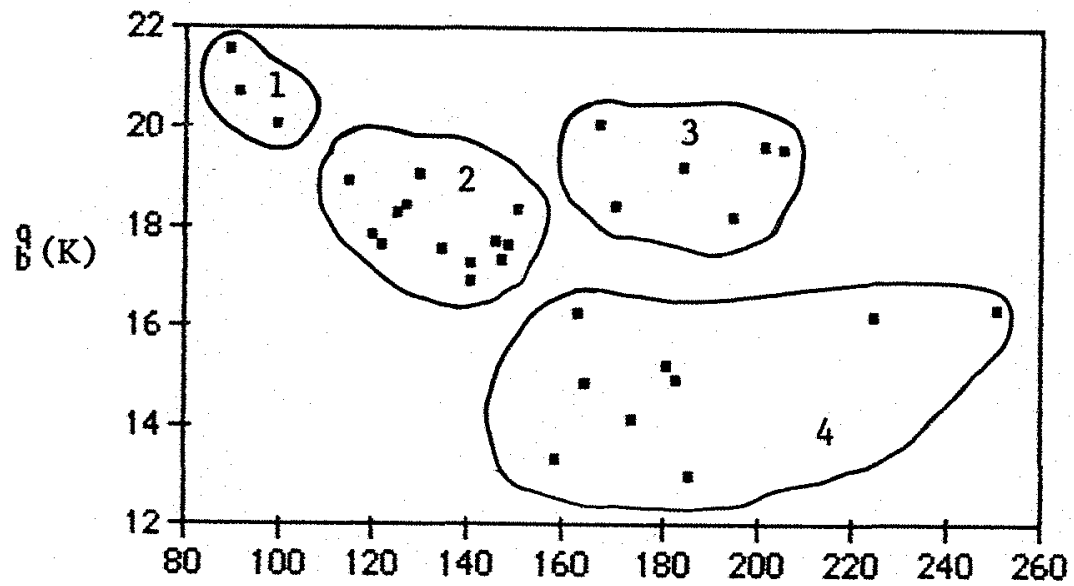

po $(\mathrm{Cz} \$ 2$

Figura 1. Quantidade consumida de carne bovina versus preço de carne bovina-período 1957-87

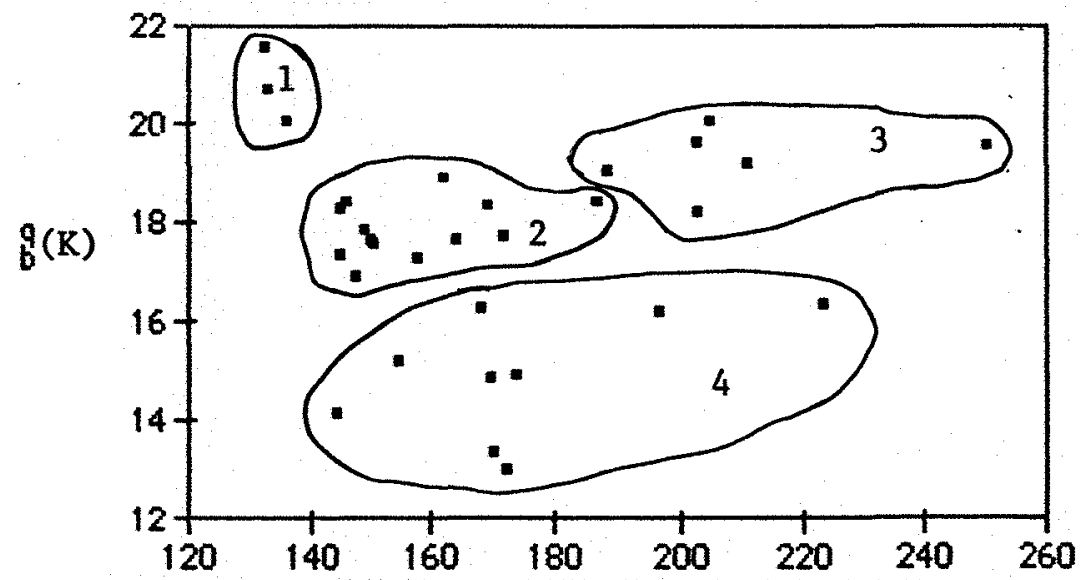

ps $(\mathrm{Cz} \$)$

Figura 2. Quantidade consumida de carne bovina versus preço

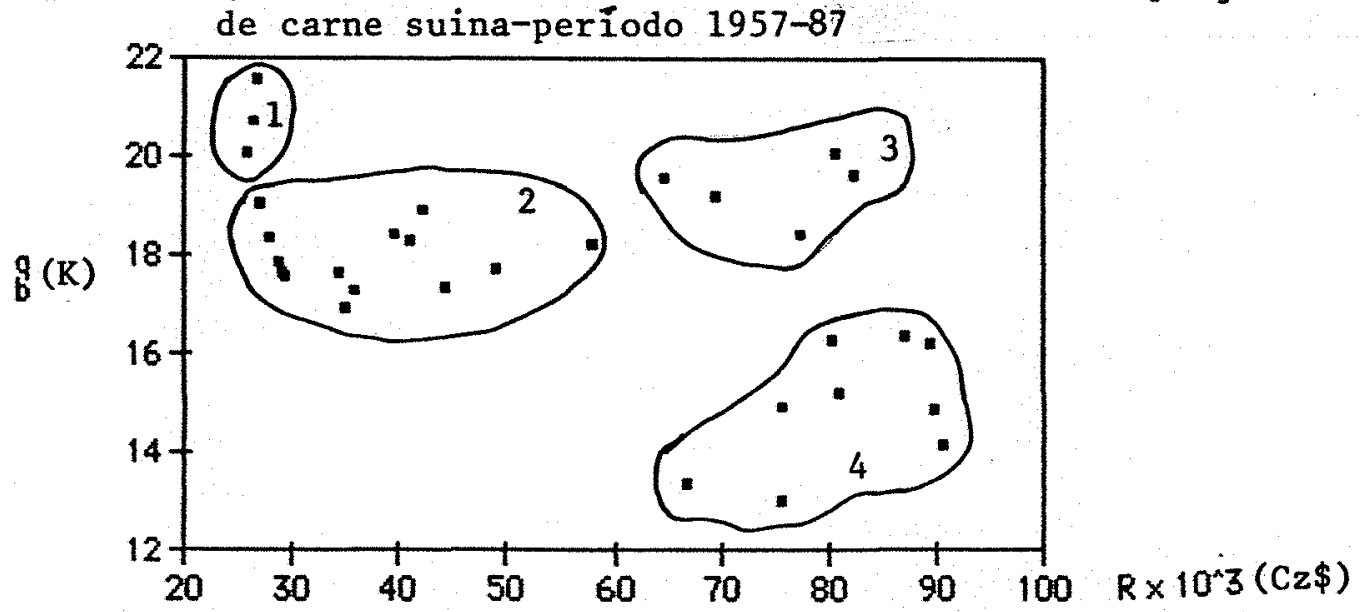

Figura 3. Quantidade consumida de carne bovina versus rendaperíodo $1957-87$ 


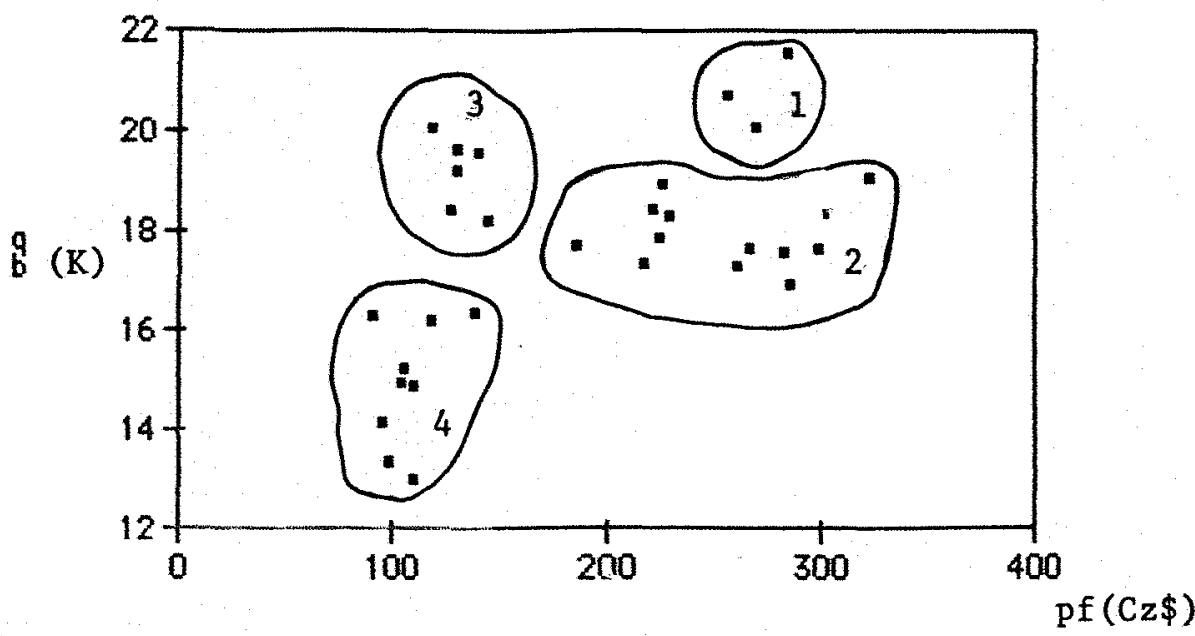

Figura 4. Quantidade consumida de carne bovina versus preço de frango - período 1957-87

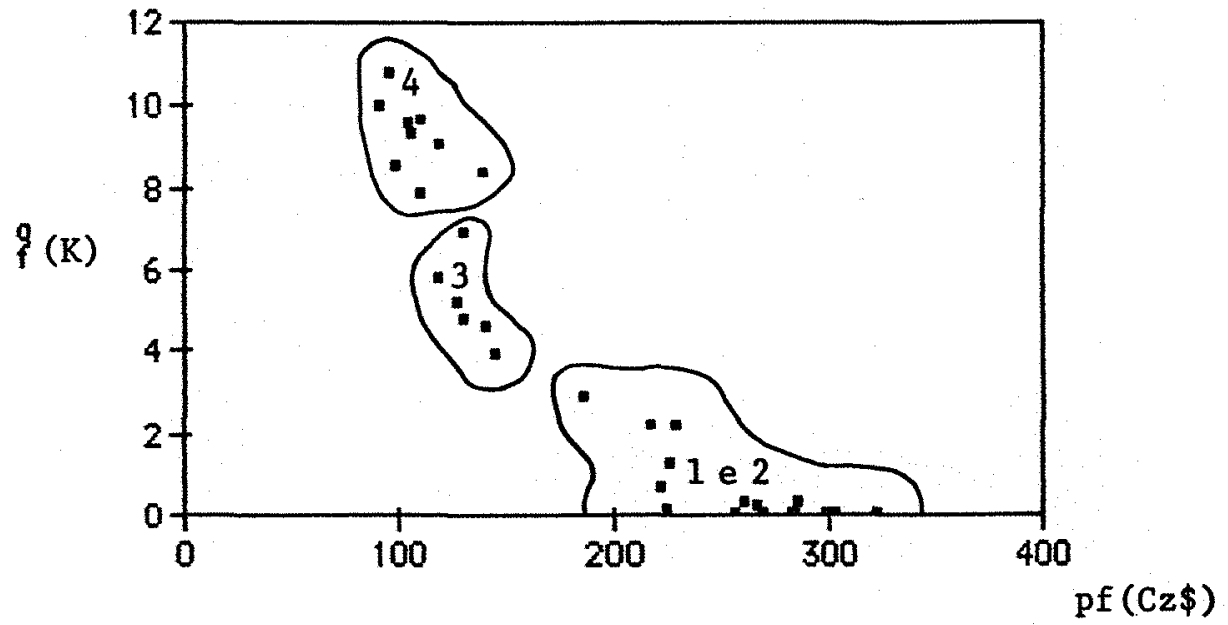

Figura 5. Quantidade consumida de carne de frango versus pre ço de carne de frango-período 1957-87 
renda ao longo da série em anālise. Nessas figuras, os pontos circundados identificam agrupamentos de dados por periodos, que mostram, visualmente, o comportamento da demanda de carne bovina em função dos preços e renda dos consumidores. 0 agrupamento 1 se refere ao período 1957-59, o 2 ao período $1960-72$, o 3 ao período $1973-78$ e o 4 ao período 1979-87. A Figura 5 mostra as relações entre o consumo de carne de frango e o seu pre ço, estando, neste caso, os agrupamentos 1 e 2 reunidos num só grupo devido a impossibilidade de separar graficamente os seus pontos.

Na Figura 1 verifica-se, pelo posicionamento dos agrupamen tos 1,2 e 4, uma queda nas quantidades consumidas de carne bovina, durante a sērie em anālise, estando essa queda relacionada a um aúmento do preço. No período 3, entretanto, ocorreu um aumento na quantidade consumida de carne bovina em relação ao período 2, apesar dos preços se manterem em patamares maiores no período 3. Essa inversão ocorrida no consumo de carne bovina, frente às variações de seu preço, nesses períodos, pode estar relacionada com o aumento elevado da renda "per capita" ocorrida no período 3 em relação ao 2 , conforme mostra a Figura 3 .

Pode-se observar, nesta Figura 3 , que a quantidade consumida de carne bovina está relacionada positivamente à renda "per capita", se considerar-se os agrupamentos 2 e 3. Verifica-se uma queda no consumo no período 4, fato este que pode estar associado ao crescimento do consumo de carnes substitutas.

A Figura 2 relaciona as quantidades consumidas de carne bovina aos preços de carne suína. Observa-se, atravês dela, considerando os períodos 2 e 3, um aumento nos preços de carne suína acompanhado de 
um aumento nas quantidades consumidas de carne bovina. No período 4 identifica-se um deslocamento para baixo na relação quantidade consumida de carne bovina - preço suíno, possivelmente devido a maior disponibilidade de carnes substitutas.

Nas Figuras 4 e 5 , pode-se facilmente visualizar a redução do consumo de carne bovina ocorrida durante o período em análise e sua relação com a queda no preço de frango. A Figura 5 que correlaciona as quan tidades consumidas de carne de frango aos seus preços, mostra uma forte tendência crescente do consumo desse produto, estando esse consumo negativamente correlacionado ao seu preço. Na Figura 4 fica claro, pela posição dos agrupamentos 1 e 4, a existência de uma correlação positiva entre - consumo de carne bovina e o preço de frango (consumo elevado a preços elevados e vice-versa). No caso do período 2, todavia, mesmo tendo os pre ços de carne de frango se mantido nos mesmos níveis do período 1 , houve uma queda na quantidade consumida de carne bovina. No período $3 \mathrm{em}$ relação ao 2, ocorreu um aumento na quantidade consumida de carne bovina apesar da diminuição dos preços de carne de frango.

Uma avaliação quantitativa dessas tendências diferenciadas de comportamento foi feita utilizando-se uma análise de regressão relacionando o consumo de carne bovina ( $q b$ ) com os preços dos diferentes tipos de carne e renda dos consumidores, introduzindo-se na função a variāvel bināria (Dummy) que permite a verificação da significância estatística das variações de inclinação e intersecção das relações estudas para diferentes períodos da série. A verificação da variação da inclinação é feịta atravēs da análise de significância do coeficiente da variável interação (B.p ou $B \cdot R$ onde $B=$ variāvel binäria, $p=$ preço e $R=$ renda) e $\quad a$ 
variação da interseç̧ão è feita atravēs da anālise de significância do coe ficiente da variāvel bināria B. Para a referida análise, a série foi dividida em dois períodos: 1957-72 e 1973-87, periodos estes caracterizados por menor e maior representatividade da carne de frango dentro do grupo de carnes mais consumidas.

A Tabela 4 mostra os resultados obtidos para as regressões referentes aos dados das Figuras 1 a 4 .

Com base na Tabela 4 as seguintes observaçōes podem ser feitas quanto ao comportamento do consumo de carne bovina nos dois periodos (1957-72) e (1972-87), face às variações dos preços das diferentes carnes e renda dos consumidores:

a) Consumo de carne bovina versus preço de carne bovina

A não significância do coeficiente da variāvel interação (B.pb) mostra a não existência de diferença entre o primeiro e o segundo período quanto à inclinação da curva de consumo de carne bovina em função de seu preço. 0 coeficiente da variável binäria (B) apresentou-se significativo indicando um deslocamento paralelo da função de um período para outro. 0 sinal negativo desse coeficiente indica que, a um dado preço, todas as outras coisas permanecendo constantes, a quantidade consumida de carne bovina $\bar{e}$ menor no segundo período do que no primeiro. Uma das possíveís razóes para a ocorrência desse deslocamento da função pode ser o aumento da disponibilidade da carne de frango no mercado brasileiro, no segundo período. 
Tabela 4. Coeficientes das regressões : consumo de carne bovina versus preço de carne bovina, preço de carne suína, preço de frango e renda (incluindo a variável binária e suas interaçōes). Pe rỉodo $1957-87$

\begin{tabular}{|c|c|c|}
\hline Variāveis Independentes & Coeficiente & $\underset{\%}{\text { Nível de significância }}$ \\
\hline \multicolumn{3}{|l|}{ preço do bovino } \\
\hline constante & 21.900 & 1 \\
\hline $\mathrm{pb}$ & -0.028 & - \\
\hline $\mathrm{B}-\mathrm{pb}$ & 0.016 & - \\
\hline B & -3.148 & 10 \\
\hline & & \\
\hline \multicolumn{3}{|l|}{ preço do suino } \\
\hline constante & 12.986 & 1 \\
\hline ps & 0.035 & 10 \\
\hline B-ps & -0.002 & - \\
\hline B & -2.275 & - \\
\hline \multicolumn{3}{|l|}{ preço do frango } \\
\hline constante & 12.515 & 1 \\
\hline $\mathrm{pf}$ & 0.023 & 5 \\
\hline$B-p f$ & 0.025 & 5 \\
\hline B & -1.622 & - \\
\hline & & \\
\hline \multicolumn{3}{|l|}{ renda } \\
\hline constante & 21.327 & 1 \\
\hline $\mathbf{R}$ & 0.000 & - \\
\hline $\mathrm{B}-\mathrm{R}$ & -0.538 & - \\
\hline $\mathrm{B}$ & -0.000 & - \\
\hline
\end{tabular}


b) Consumo de carne bovina versus preço de carne suína

Neste caso, tanto o coeficiente da variável binária

como o da variável interação (B.ps) apresentaram-se não significativos, indicando a não existência de mudanças da intersecção e da inclinação da função estudada, de um período para outro.

c) Consumo de carne bovina versus renda

Também nesse caso, tanto o coeficiente da variável binária como o da variável interação apresentaram-se não significativos.

d) Consumo de carne bovina versus preço de frango

0 coeficiente da variāvel interação apresentou-se significativo enquanto que o coeficiente da variāvel bināria não, indicando que ocorreu apenas variação na inclinação da curva entre os períodos considerados. A variação ocorrida na inclinação da função indica que no segundo período, a uma unidade de variação do preço de carne de frango ocor re uma variação do consumo de carne bovina maior que no primeiro perỉodo. Esse fato sugere um maior grau de substituibilidade entre carne bovina e de frango no segundo perỉodo. 


\subsection{Anālise Estatística}

Os resultados estatísticos encontrados para o ajuste da equação completa de demanda de carne bovina, especificada neste estudo são apresentados na Tabela 5 .

0 Teste "F" mostrou-se significativo a $1 \%$ de probabilidade, indicando que pelo menos uma das variáveis independentes apresenta correlação significativa com a variāvel dependente.

Corroborando o resultado encontrado para o teste "F", obte ve-se alto valor para o coeficiente de determinação mültipla $\bar{R}^{2}$, mostrando que $99,7 \%$ das variações ocorridas na variâvel dependente são explicadas pelas variações das variāveis independentes incluídas na equação.

Verificou-se, pela estatística "Q", a não existência de correlação serial nos resíduos, condição necessária para a utilização do método de mínimos quadrados ordinārios.

Os coeficientes das variáveis preço de carne bovina, preço de carne suína e renda apresentaram-se significativos (estatisticamente diferentes de zerol ao nível de $1 \%$ ou $5 \%$ de probabilidade, e com sinais coerentes com a teoria econômica e com os conhecimentos empíri$\cos$.

0 coeficiente da variáve1 preço de frango apresentou-se positivo indicando existir algum grau de substituibilidade entre as carnes bovina e de frango. Todavia, ele apresentou-se não significativo. 


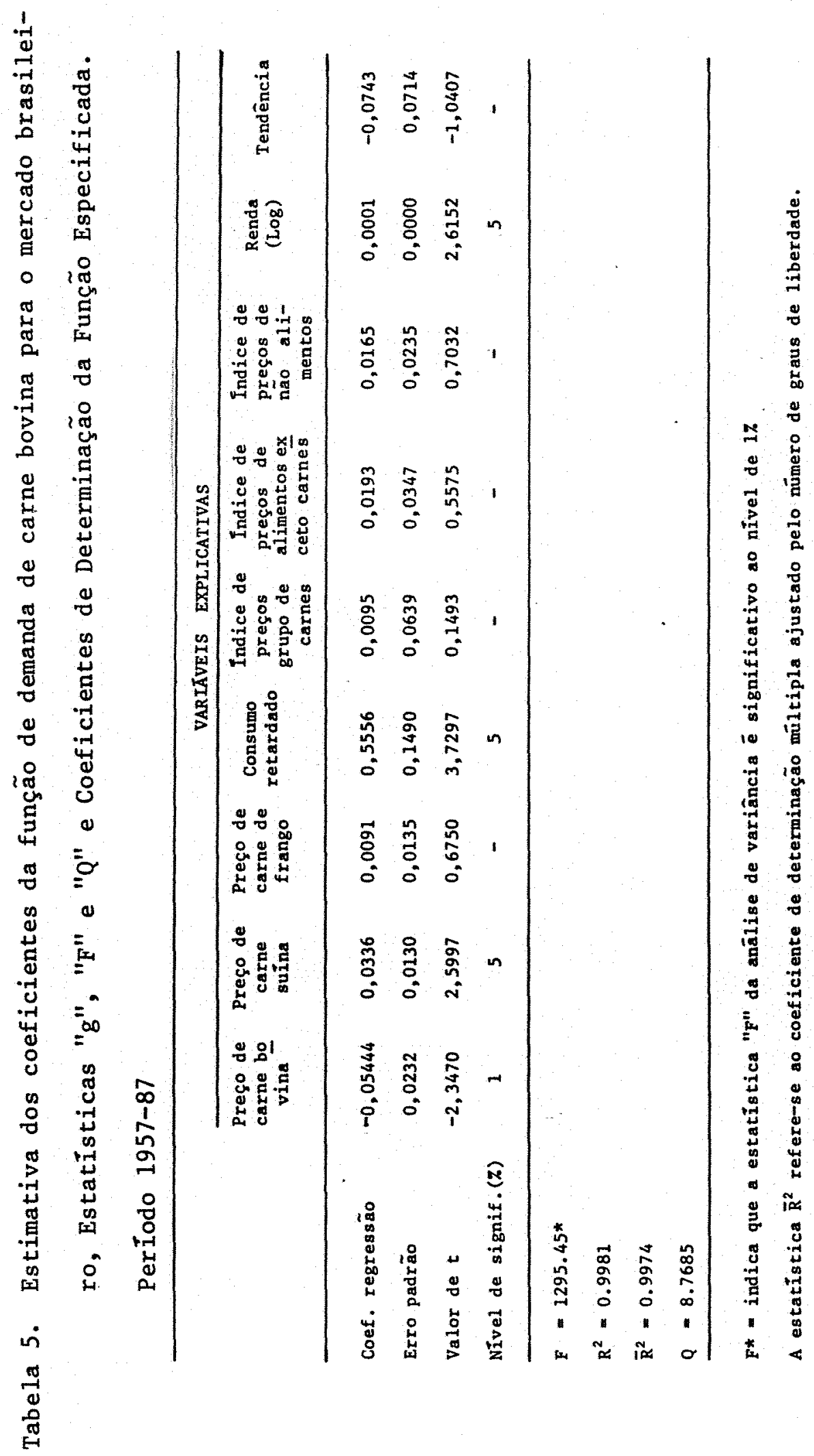


Uma vez que foram incorporados na função de demanda dados recentes de mer cado, período em que o frango passa a ter representatividade no consumo do povo brasileiro esperava-se um coeficiente significativo. Pelo menos duas possibilidades podem ser formuladas para explicar essa divergéncia no resultado encontrado. A primeira está relacionada a problemas empíricos associados aos dados utilizados. O comércio varejista para a carne de frango não era bem definido para os primeiros períodos da série, dificultando a determinação de um preço médio representativo para a época em que grande parte das transaçôes eram realizadas atravês do comércio informal. A segunda possibilidade está relacionada à existéncia de multicolinearidade entre as variáveis que pode fazer com qua alguns dos coeficientes de regressão mültipla se apresentem estatisticamente não diferentes de zero, embora sejam importantes no modelo teórico ${ }^{27}$.

Quanto aos coeficientes das variáveis referentes aos indices de preços, todos apresentaram-se não significativos nos níveis de probabilidade considerados. 0 mesmo ocorreu com a variável tendência.

Tendo-se observado então, a existência de coeficientes não significativos na função estimada, pesquisou-se a ocorrência de multicolinearidade entre as variáveis dependentes, através dos resultados da matriz de correlação simples. Verificou-se que as variáveis renda e tendência, tendência e preço de frango e preço de frango e renda eram altamente correlacionadas. Tentou-se excluir do modelo a variável tendência que, dessas variâveis citadas, era a que apresentava menor significado econômico. Todavia, os resultados estatísticos encontrados não

27 Ver HOFFMANN \& VIEIRA (1983), p.158. 
foram superiores, tendo-se optado por proceder à análise econômica através dos coeficientes da função inicialmente especificada, apesar da impossibilidade de se obter boa estimativa da relação entre consumo de carne bovina e preço de frango, que era um dos objetivos deste trabalho.

0 valor do coeficiente de ajustamento $(\delta)$, calculado

a

partir do resultado encontrado para o coeficiente da variável consumo de carne bovina defasado, é de 0,44 , indicando que o ajuste entre os dois períodos é igual a $44,4 \%$ da diferença entre o consumo observado e o obtido no equilíbrio de longo prazo. En outras palavras, 44,4\% da diferença entre a quantidade desejada e a observada é eliminada em um ano.

A forma linear da equação utilizada implica em demanda mais elástica a níveis elevados de preço, tornando-se inelástica à medida que os preços vão declinando. No caso da carne bovina, que ê um produto caro, dado o poder aquisitivo do povo brasileiro, espera-se que haja um declínio maior do consumo a nível de preços elevados, do que a preços baixos, isso considerando que, mesmo a preços elevados, existam consumidores de baixo poder aquisitivo. Esse comportamento e, portanto, coerente com a forma linear da equação de demanda, cuja elasticidade-preço $\bar{e}$ dada por : $E=\pi . P / Q$. Todavia, como alguns dos resultados empiricos obtidos com a especificação proposta neste trabalho não foram satisfatôrios, procedeu-se, para fins de comparação, o ajuste da função na forma bi-logarítmica (exceto a variável tendência que foi expressa nos números naturais), apesar da menor consistência teôrica dessa especificação que implica em elasticidade de demanda constante dentro do 
intervalo utilizado para estimação $(E=b$, onde $b=$ valor do coeficiente). Os resultados estatisticos obtidos, entretanto, foram inferiores.

Ajustou-se ainda, como uma variante do modelo inicialmente proposto, a função de demanda incluindo-se uma constante e tendo a renda expressa no logaritmo neperiano dos valores observados, mesmo não sendo, essa função, embasada numa função de utilidade específica e conhecida, como no primeiro caso. Para a variável renda, a relação linear parece não ser a mais indicada uma vez que ela implica em elasticidades maiores para rendas maiores. A literatura consultada demonstra que a relação existente é exatamente a oposta. Quando a renda é baixa e a percentagem desta gasta com produtos alimentares é relativamente alta, a reação da demanda de um alimento frente às variaçôes no seu preço é maior do que quando a renda é alta e a percentagem desta gasta com alimentação baixa. A elasticidade renda obtida com a renda expressa no logaritmo varía em relação inversa à quantidade consumida $(E=\pi / Q)$, sendo esta ūltima diretamente relacionada à renda.

Os resultados obtidos com 0 ajuste da função com constante e renda expressa nos logaritmos dos valores observados são apresentados na Tabela 6 .

Assim como na primeira equação ajustada verificou-se alto valor para o coeficiente determinação múltipla $\left(\bar{R}^{2}=0,9292\right)$ e a não existência de correlação serial nos resíduos $(Q=9,6660)$. 


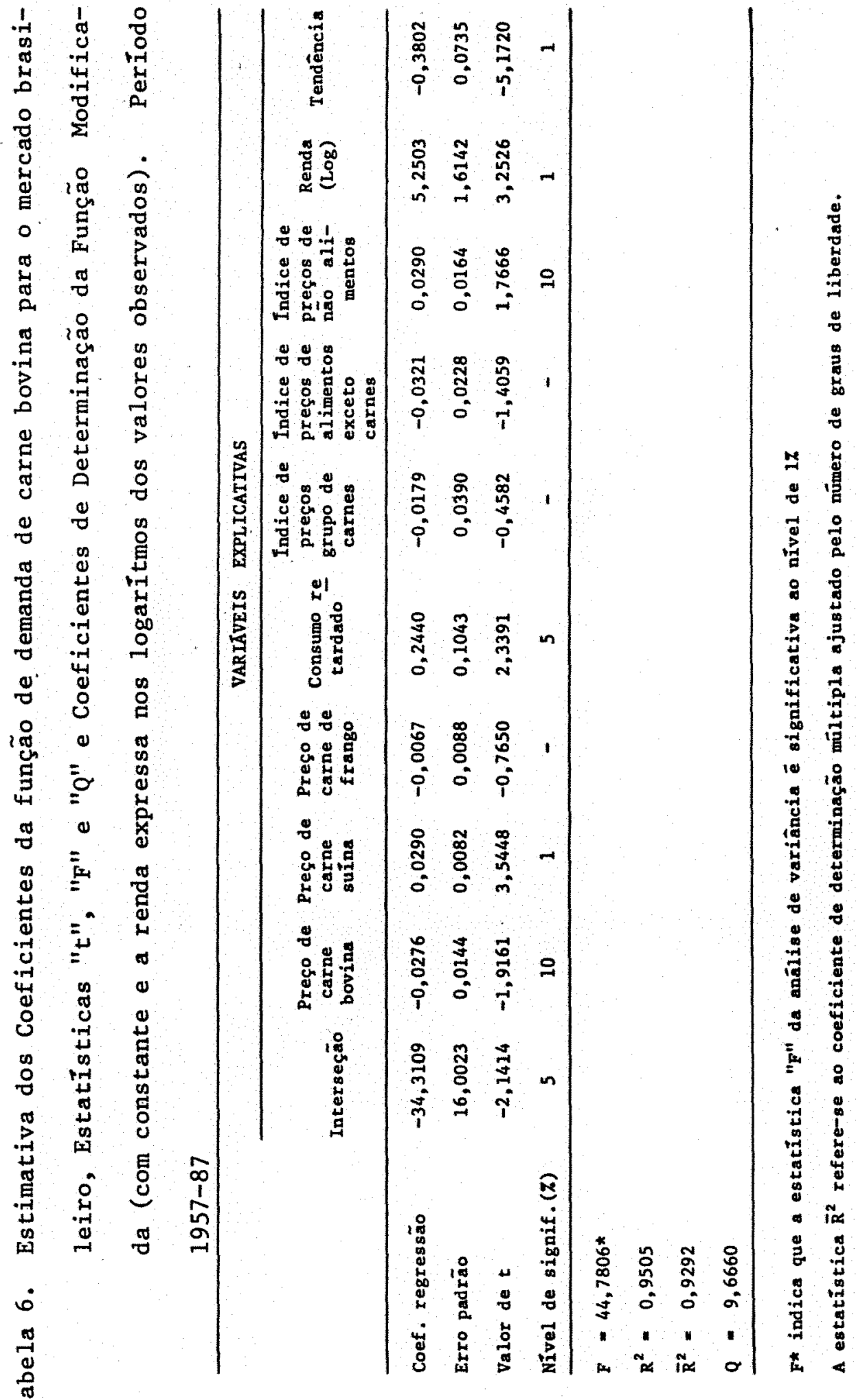


Tambēm nesta função os coeficientes das variāveis preço de carne bovina, preço de carne suỉna e renda apresentaram-se significativos para os niveis de probabilidade considerados, 1,5 ou $10 \%$ e com sinais coe rentes com a teoria e com os conhecimentos empiricos.

o coeficiente da variável tendência mostrou-se significativo e negativo, o que indica que o consumo de carne bovina, durante o período em estudo, apresenta uma tendência decrescente no tempo.

0 coeficiente da variável preço de frango apresentou-se negativo e não significativo, divergindo, no que se refere ao sinal, do encontrado na primeira equação.

Quanto aos indices de preço apenas o do grupo "não alimentos" apresentou-se significativo aos niveis de probabilidade considerados.

o coeficiente da variável dependente defasada apresentouse significativo e positivo. o valor do coeficiente de ajustamento calculado a partir do resultado encontrado para esse coeficiente da variävel dependente defasada é de 0,756 indicando que $75,6 \%$ da diferença entre a quantidade desejada e a observada ê eliminada em um período (um ano).

\subsection{Anälise Econômica}

As elasticidades encontradas para a demanda de carne bovina, calculadas nas médias amostrais, para curto e longo prazos, são apresentadas na Tabela 7 . 
Tabela 7. Elasticidades de demanda de carne bovina calculadas nas médias amostrais para curto e longo prazos e fórmulas utilizadas para a obtenção dessas elasticidades.

\begin{tabular}{|c|c|c|c|c|}
\hline \multirow{2}{*}{ Elasticidảdes } & \multicolumn{2}{|c|}{ Curto prazo } & \multicolumn{2}{|c|}{ Longo prazo } \\
\hline & Valor & Fórmula & Valor & Fórmula \\
\hline preço-direta* & $-0,48$ & $\pi_{1} \cdot \frac{\overline{\mathrm{P}}_{\mathrm{B}}}{\overline{\mathrm{Q}}_{\mathrm{B}}}$ & $-1,09$ & $\frac{E_{d}}{\delta}$ \\
\hline $\begin{array}{l}\text { cruzada com preço } \\
\text { de frango** }\end{array}$ & 0,10 & $\pi_{3} \cdot \frac{\overline{\mathrm{P}}_{F}}{\bar{Q}_{B}}$ & 0,22 & $\frac{E C_{p f}}{\delta}$ \\
\hline $\begin{array}{l}\text { cruzada com preço } \\
\text { de suino* }\end{array}$ & 0,33 & $\pi_{2} \cdot \frac{\bar{p}_{s}}{\bar{Q}_{B}}$ & 0,73 & $\frac{E C_{p s}}{\delta}$ \\
\hline renda & 0,30 & $\pi_{7} \cdot \frac{\bar{R}}{\bar{Q}_{B}}$ & 0,67 & $\frac{\mathrm{EC}_{\mathbf{r}}}{\delta}$ \\
\hline
\end{tabular}

* Esses valores tendem a se alterar ao longo da curva de demanda sendo que para preços maiores e quantidades menores as elasticidades aumen tam e vice-versa.

* Valores considerados de baixa precisão devido a não significância do coeficiente estimado $\left(\pi_{3}\right)$ 
Os resultados obtidos indicam uma inelasticidade da demanda em relação ao próprio preço, no curto prazo. No longo prazo a demanda torna-se elástica.

No curto prazo, uma variação de $10 \%$ no preço de carne bovina deve ocasionar uma variação de $4,8 \%$, em sentido conträrio, no consumo desse alimento, todas as outras coisas permanecendo constantes. No Iongo prazo, uma variação de $10 \%$ no preço desse alimento deve provocar uma variação de $10,9 \%$, em sentido contrário, no seu consumo.

Antes de qualquer tentativa de comparação dos resultados encontrados neste estudo com os de outros autores, é necessārio tecer con siderações sobre as elasticidades obtidas com dados de corte seccional e de série temporal. Nas elasticidades estimadas com dados de corte seccio nal, considera-se que todos os ajustamentos no consumo, frente às variações nos preços ou na renda dos consumidores, $j a ̈$ se tenham processado, sendo, dessa forma, comparáveis às elasticidades obtidas para longo prazo, com dados de série temporal.

Para a elasticidade-preço direta da demanda de carne bovina, os resultados encontrados na literatura consultada para dados de Brasil e de regiões específicas desse País são apresentados na Tabela 8.

Verifica-se que os valores obtidos no presente estudo para essa elasticidade-preço de curto prazo $-0,48$, e 1ongo prazo $-1,05$, en contram-se dentro da faixa de elasticidades determinadas pelos vārios autores citados. 


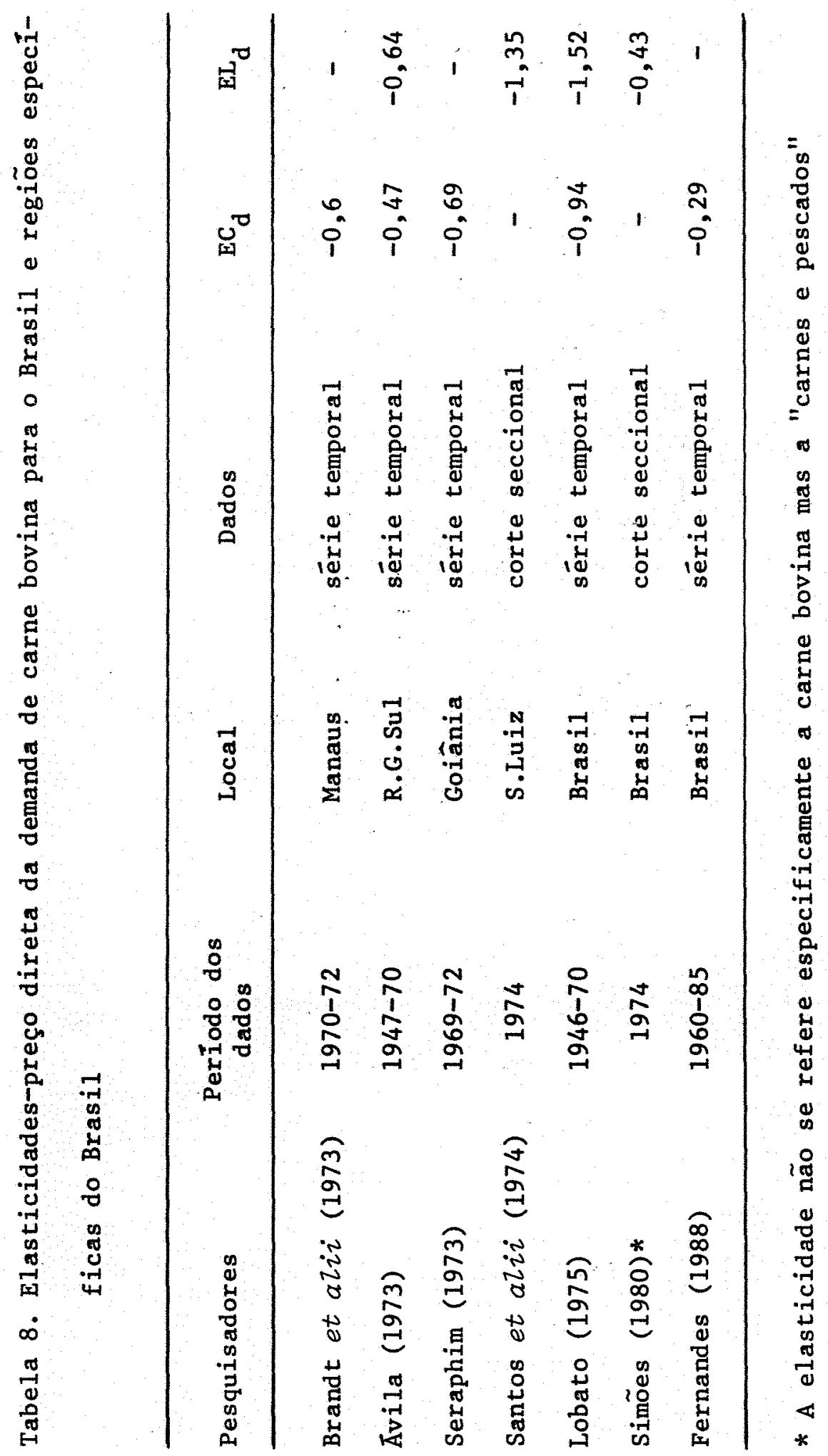


Para as elasticidades cruzadas com preço de carne suína foram encontrados os valores 0,33 e 0,73 , no curto e longo prazos, respectivamente. 0 sinal positivo desses coeficientes indica que as carnes bovina e suína são produtos substitutos. A curto prazo, uma variação de $10 \%$ no preço de carne suína deve ocasionar uma variação de $3,3 \%$, no mesmo sentido, no consumo de carne bovina. No longo prazo uma variação de $10 \%$ no preço de carne suína deve ocasionar uma variação de $7,3 \%$ no consumo de carne bovina, todas as outras permanecendo constantes.

Esse resultado encontrado para a elasticidade cruzada com preço de carne suỉna, no curto prazo, é bastante próximo do encontrado por FERNANDES (1988) $\left(E C_{\mathrm{ps}}=0,34\right)$ e bastante menor que o encontrado por LOBATO (1975) para o período 1946-70 $\left(\mathrm{EC}_{\mathrm{ps}}=1,22\right)$.

Os valores encontrados para as elasticidades cruzadas com preço de frango no curto e longo prazo $\left(\mathrm{EC}_{\mathrm{pf}}=0,10\right.$ e $\left.\mathrm{EL}_{\mathrm{pf}}=0,22\right)$ indicam que apesar de existir substituibilidade entre carne bovina e de frango, o consumo de carne bovina varia pouco em função de mudanças nos preços de carne de frango. Esses resultados diferem bastante do obtido por FERNANDES (1988), cujo valor foi de 0,84 .

Os valores estimados para as elasticidades-renda, 0,30 para curto prazo e 0,67 para longo prazo, indicam que a carne bovina, pode ser enquadrada como "bem necessário" 31 .

31 "Bens necessārios" são aqueles cujas elasticidades-renda estão no intervalo de 0 a 1 . 
Na Tabela 9 encontram-se os resultados obtidos para a elasticidade-renda da demanda de carne bovina por diversos autores.

$$
\text { Pode-se observar que as elasticidades-renda obtidas na }
$$

literatura consultada diferem em magnitude, todavia, com exceção das elasticidades encontradas por LOBATO (1975) e FERNANDES (1988), que foram bastante altas, todas as outras indicam que o consumo de carne bovina varia menos que proporcionalmente à renda.

Conquanto se refiram a carnes e pescado e não especificamente a carne bovina, os resultados obtidos por HOFFMANN (não publicados $)\left(E L_{r}=0,55\right)$ e SIMÕES $(1980)\left(E L_{r}=0,43\right)$ com dados do ano de 1974 do ENDEF, para o Brasil como um todo, estão próximos dos encontrados nes te estudo $\left(\mathrm{EC}_{\mathrm{r}}=0,30\right.$ e $\left.\mathrm{EL}_{\mathrm{r}}=0,67\right)$. Todavia, uma redução da elasticidade renda, comparativamente às obtidas naquele ano, era esperada, uma vez que foram incorporadas na função de demanda dados recentes de mercado, época em que houve aumento da renda "per capita". Como jā citado, a magnitude da elasticidade renda $\bar{e}$ inversamente relacionada a essa variāve1.

Se considerarmos essa relação inversa entre renda e elasticidade renda, teríamos para a demanda de carne bovina, no mercado norte americano, valores menores do que os encontrados no caso brasileiro. Isso realmente ocorreu no estudo de GEORGE \& KING (1971), que obteve para esta elasticidade de curto prazo o valor de 0,28 porém não no de HEIEN (1982) onde o valor obtido foi de 1,27 . 


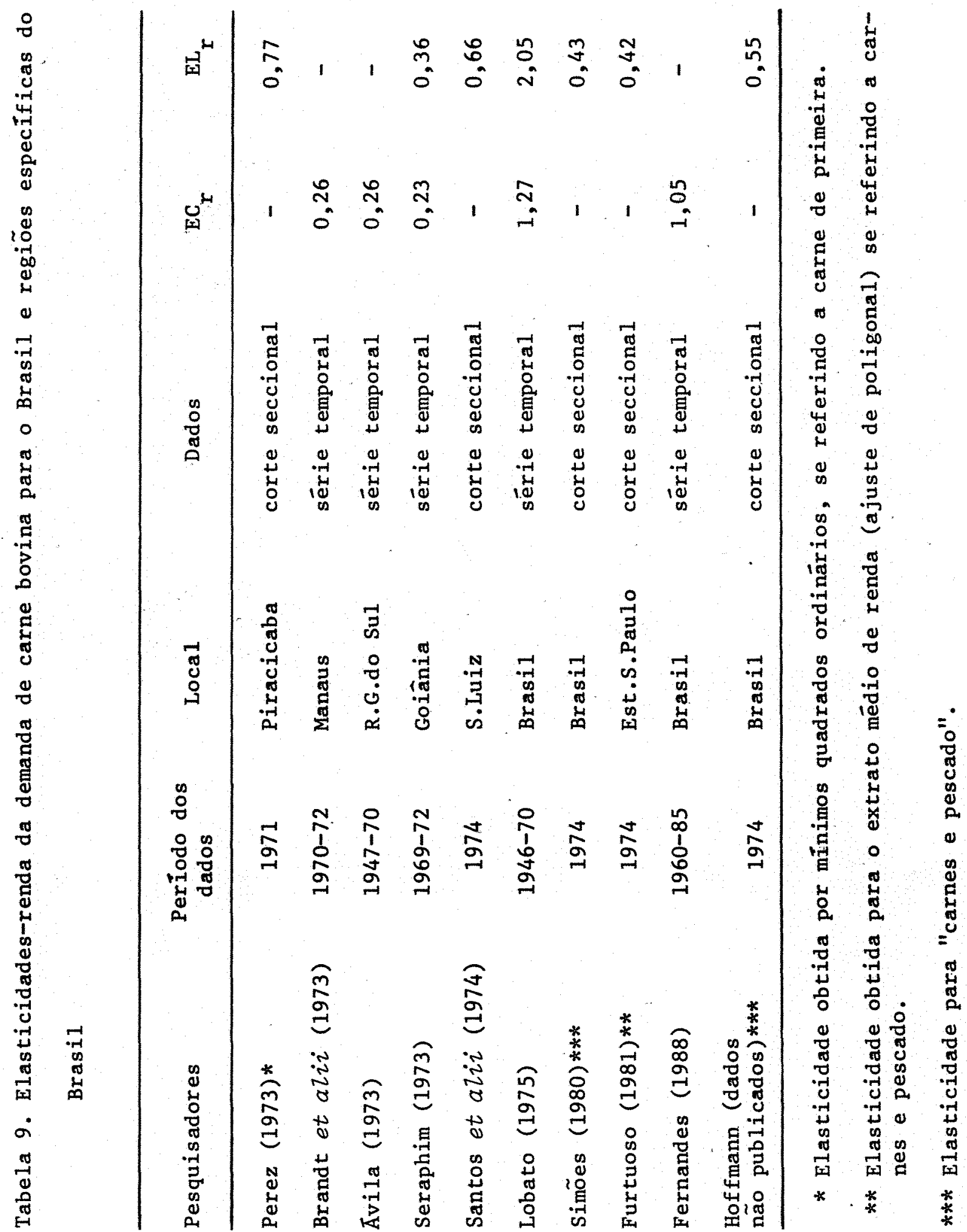


Na Tabela 10 encontram-se os valores das elasticidades obtidas com a função modificada (com constante e renda expressa nos 1ogaritmos dos valores observados). Verifica-se que, no curto prazo, a elasticidade renda obtida com a função modificada $\left(\mathrm{EC}_{\mathrm{r}}=0,30\right)$ é exatamente a mesma da obtida com a função inicialmente proposta $\left(E C_{r}=0,30\right)$. Quanto a elasticidade cruzada com preço de suíno, pouca variação ocorreu entre os valores obtidos nas duas funções $\left(E C_{p s}=0,33\right.$ na primeira e $\mathrm{EC}_{\mathrm{ps}}=0,28$ na modificada). Maior variação se deu no caso da elas ticidade-preço direta, sendo esta de $-0,48$ na primeira função e $-0,25$ na modificada.

Os valores encontrados para as elasticidades cruzadas com preço de carne de frango (curto e longo prazo), ao contrário dos obtidos com a função inicialmente proposta, sugerem a existência de complementaridade entre a carne de frango e a carne bovina o que contraria os conhecimentos empíricos.

Os valores obtidos para as elasticidades de longo prazo foram, em todos os casos (direta, cruzadas com preço de suíno e frango e renda), menores na função modificada visto esta apresentar um coeficiente de ajustamento $(\delta)$ maior que a primeira.

\subsection{Período de Ajustamento}

o período necessārio para a demanda observada atingir a de longo prazo é dado pela fórmula: 
Tabela 10. Elasticidades de demanda de carne bovina calculadas nas mé dias amostrais para curto e longo prazos com a função mo dificada (com constante e renda expressa nos logaritmos dos valores observados)

* A elasticidade renda varia em relação inversa à quantidade consumida, sendo esta ūltima diretamente rełacionada à renda.

** Valores considerados de baixa precisão, devido a não significância do coeficiente estimado. 


$$
t=\frac{\ln (1-\alpha)}{\ln (1-\delta)}
$$

onde:

$\delta$ é o coeficiente de ajustamento calculado em $44,4 \%$ e $\alpha$ uma proporção arbitrária do ajustamento total, tomada aqui como $98 \%$, que quando com plementada simboliza o pleno ajustamento. 0 valor encontrado para $t$ foi de 6,7 significando que 6 anos e 8 meses serão necessários para a demanda observada atingir a desejada, todas as outras coisas permanecendo cons tantes.

o valor encontrado para $t$ no caso da função modificada foi bastante menor do que o encontrado com a função proposta neste estudo, funda mentada numa função de utilidade específica tipo Stone-Geary. 0 valor do coeficiente de ajustamento obtido com a função modificada foi calculado em $75,6 \%$ e o de $t$ em 2,8 , o que significa que 2 anos e 10 meses serão necessários para a demanda observada atingir a desejada.

SERAPHIM (1973) encontrou, trabalhando com dados mensais do perî́odo 1969-72 da cidade de Goiānia, Goiäs, o tempo de 4 meses para a demanda observada se ajustar à desejada. Os outros autores consultados não determinaram esse dado. 
5. CONCLUSÕES

A evolução do mercado de carnes no período estudado (1957-87) apresentou as seguintes caraeterísticas com relação ao fator disponibilidade: diminuição na de carne bovina, aumento na de carne de frango e estabilidade na de carne suína.

o maior aumento na disponibilidade de carne de fran go ocorreu na ültima década da sērie estudada, como consequência do desenvolvimento da avicultura e consequente queda dos preços de seu produto. Nesse período as relações salário mỉnimo/preço de carne bovina foram as menores, coincidindo com baixas relações $(<1)$ de preço de frango/preço de bovino e preço de frango/preço de sui no, condição essa favorável ao: maior consumo da carne de frango em relação às outras carnes.

Os testes aplicados para a verificação do consumo dí ferenciado de carne bovina ao longo da série em estudo, através da utilização da variāvel binária, demonstraram que a quantidade 
consumida de carne bovina, a um dado preço, é menor na segunda metade da série. Verificou-se também que nessa segunda metade da série a variação no consumo de carne bovina é maior que na primeira metade da série para cada unidade de variação no preço de carne de frango o que sugere um maior grau de substituibilidade entre carne bovina e de frango no segundo período.

Quanto ao estabelecimento do modelo econométrico na anālise da demanda de carne bovina, a equação especificada, fundamentada numa função de utilidade separável mostrou-se adequada na estimativa das elasticidades uma vez que os valores encontrados são com parāveis àqueles obtidos por outros autores. A inclusão dos indices de preço na função de demanda torna viável a estimativa das elastici dades, fundamentada na teoria economica, para séries curtas de dados disponíveis.

As maiores dificuldades encontradas na aplicação do modelo se devem a não existência de sêries homogêneas de dados quanto a fonte e metodologia de coleta. Pode-se considerar também que os abates clandestinos, não computados nas estatísticas existentes, in terferem na fidedignidade dos dados.

Os resultados obtidos com o modelo econométrico propos to neste estudo permitem concluir que o consumo de carne bovina é pouco sensível às variações na renda dos consumidores, sendo mais sen sível às variações de seu proprio preço. 
Apesar do coeficiente da variāvel preço de frango não ter-se apresentado significativo, e a elasticidade encontrada ser muito baixa, a hipótese de existência de correlação entre essa variā vel e o consumo de carne bovina não pode ser descartada, preferindose acreditar que a qualidade dos dados utilizados ou problemas de ordem economētrica é que não permitiram que a real correlação fosse detectada. Todavia, esse coeficiente apresentou-se positivo o que sugere a existência de algum grau de substituibilidade entre carne bovina e de frango.

A elasticidade cruzada de demanda de carne bovina, em relação ao preço de carne suína, indica baixo grau de substituibili dade entre esses dois produtos.

As elasticidades obtidas permitem ainda concluir que a quantidade demandada de carne bovina torna-se mais sensivel às va riações ocorridas em seu preço, no preço de carne suína e na renda dos consumidores à medida que o tempo passa. Todavia, tanto a cur to como a longo prazo, a quantidade de carne bovina varia menos que proporcionalmente frente às mudanças nessas variáveis citadas, exces são feita às variações ocorridas no consumo de carne bovina devido a variações em seu próprio preço.

Com os resultados encontrados pode-se concluir que pouco efeito no consumo de carne bovina teriam políticas que inter viessem nos preços de carne suina, dada a constatação de que esses produtos são francamente substituidos. Maiores resultados teriam 
politicas que interviessem nos preços de carne bovina.

Esses resultados encontrados sinalizam importantes implicações para a definição de polîticas econômicas para o setor. A criação de excedentes exportáveis de carne bovina, que tem sido uma das preocupações governamentais frente a um promissor mercado externo, seria possível então, através de estímulos à sua produção, intervenção nos seus preços, ou através de campanhas e propagandas que incentivassem a redução de seu consumo interno e aumento do consumo de bens substitutos.

A magnitude da elasticidade-renda encontrada também possui implicações polîticas para o setor. As elasticidades obtidas indicam que o crescimento da renda "per capita" no Brasil teria uma influên cia pequena sobre os níveis de consumo de carne bovina. Isso significa que o deslocamento da curva de demanda, que resulta de variações na renda "per capita", è baixa, tendo portanto pequeno efeito sobre o consumo desse alimento. Dessa forma, pretendendo-se manter os níveis de preço, estímulos à produção de carne bovina, frente à expectativa de aumento de renda, devem ser tais que permitam que a produção aumente menos que proporcionalmente à variação prevista para renda. No caso de importação tam bëm esse fator deve ser considerado. 
REFERÊNCIAS BIBLIOGRĀFICAS

ANUĀRIO ESTATISTICO DO BRASIL. Rio de Janeiro, FIBGE, 1960-86, v.21-47.

AVICULTURA, Agroanalysis. Rio de Janeiro, $12(1): 2-6$, jan. 1988.

ÁVILA, A.F. Um modelo econométrico para carne bovina no Rio Grande do Sul, 1947-70. Viçosa, 1973. 67p. (Mestrado - Universidade Federal de Viçosa).

AZEVEDO FILHO, A.J.B.V.; NEVES, E.M.; MARTINES FILHO, J.G. Confinamento de Bovinos: serviços e "software" para apoio ao produtor. Revista ADEALQ, $5: 42-57,1987$.

BARROS, G.S.de C. Economia da Comercializacão Agricola. Piracicaba, SP, FEALQ, 1987. 306p. 
BISHOP, R.V. The construction and use of causality tests. Agricultural Economics Research, $31(4): 1-6,1979$.

BRANDT, S.A.; AAD NETO, A.; REZENDE, A.M.; SOUZA, A.F.; SOUZA, D.C. Anălise econômica e projegôes de demanda de came bovina no mercado de Manaus. Manaus, ACAR, 1973. 106p. (Estudos de Economia Agrícola, 3).

BURNQUIST, H.L. A questão da causalidade entre preços a diferentes níveis de mercados agrícolas. Piracicaba, 1986. 83p. (Mestrado - Escola Superior de Agricultura "Luiz de Queiroz"/UPS).

CANTO, W.L.do. Sistema Ponderal de Conversões e Determinação de Margens de Comercialização. Estudos Econômicos - Alimentos. Processados, Campinas, (22), 1988.

CONJUNTURA ECONÔMICA, FGV. Rio de Janeiro, 1971-87, vo1. 25-41.

DEATON, A. \& MUELLBAUER, J. Economics and consumer behaviour. Cambridge University Press, 1980. 446p.

DOAN, T.A. \& LITTERMAN, R.B. User's manual; rats. Minneapolis, MN: VAR Econometrics, 1981. 525p.

ENDO, S.K. \& CARMO, H.C.E.do. Breve Histórico do Indice de Preços ao Consumidor no Município de São Paulo. São Paulo, 1985. (Mimeo.). 
ETAC MERCADOS-CARNES. Curitiba, vol. III, set. 1987. (Mimeo.).

FERNANDES, S.G. Análise de Alternativas de políticas para o setor de car nes no Brasil. Viçosa, 1988. 74p. (Mestrado - Universidade Federal de Viçosa).

FRISCH, R. A complete scheme for computing all direct and cross demand elasticities in model with many sectors. Econometrica, Chicago, 27 (2): 177-96, 1959 .

FURTUOSo, M.C.o. Redistribuição de renda e consumo de alimentos no Estado de São Paulo. Piracicaba, SP, 1981. 106p. (Mestrado - Escola Su perior de Agricultura "Luiz de Queiroz"/USP).

GEORGE, P.S. \& KING, G.A. Consumer demand for food commodities in the U.S. with projections for 1980. California, University of California, 1971. 161p.

GOLDMAN, S.M. \& USAWA, H. A note on separability in demand analysis. Econometrica, Chicago, 32(3):387-97, July, 1964.

GREEN, H.A.J. Consumer Theory. England. Penguin Books Ltda., 1971. $344 \mathrm{p}$.

HEIEM, D.M. The structure of food demand: interrelatedness and quality, American Journal Economics, Iowa, 64(2):213-21, may, 1982. 
HENDERSON, J.M. \& QUANDT, R.E. Microeconomic theory: A mathematical approach. New York, McGraw-Hi11, 1971. 431p.

HOFFMANN, R. \& VIEIRA, S. Anālise de regressão: uma introdução à econometria, 2.ed. São Paulo. Hucitec. 1983. $379 \mathrm{p}$.

KASSOUF, A.L. Previsão de preço na pecuäria de corte do Estado de São Paulo. Piracicaba, 1988. 98p. (Mestrado-Escola Superior de Agricultura "Luiz de Queiroz"/USP).

KMENTA, J. Elementos de econometria. São Paulo. Atlas, 1978. 670p.

LATTIMORE, R.G. An econometric study of the brazilian beef sector. Purdue, 1974. 176p. (Doutorado - Purdue University).

LOBATO, J.G. Elasticidades parciais e totais de demanda e oferta de carnes bovina e suỉna no mercado brasileiro. Viçosa, 1975, 56p. (Mestrado - Universidade Federal de Viçosa).

LOBATO, J.G. Sistema de demanda de carnes no Brasil: uma anālise de multiplicadores. Viçosa, 1982. 61p. (Doutorado-Universidade Federa1 de Viçosa).

MARTINES FILHO, J.G. Margens de Comercialização e Causalidade de Preços Agrícolas. Piracicaba, 1988, 146p. (Mestrado-Escola Superior de Agricultura "Luiz de Queiroz"/USP). 
MASCOLO, J.C. Um estudo econométrico de pecuāria de corte no Brasil. Rio de Janeiro, 1980. 100p. (Doutorado - Fundação Getūlio Vargas).

MOLINARI, P.R. Carne Bovina em 1988 - Perpsectivas. Revista Nacional da Carne, São Paulo, 12(136):38-41, abr. 1988.

MOREIRA, H.A. Contribuição das ciências agrārias para o desenvolvimento: pecuāria bovina. Revista de Economia Rural. Brasīila, 18(3):537-57, ju1./set. 1980 .

MUELLER, C.C. O ciclo do gado e as tentativas governamentais de controle do preço da carne. Estudos Econômicos. São Paulo, 17(3):435-57. set.j dez. 1987.

NERLOVE, M. Distributed Lags and Demand Analysis for Agricultural and other Commodities, U.S.D.A.Agricultural Marketing Service Agricultural Handbook 141, Washington, D.C. 1958

NEVES, E.M.; AZEVEDO FILHO, A.V.B.V.de e MARTINES FILHO, J.G. Sistema de Produção na Pecuāria de Corte: Contribuição da pesquisa e condicionantes do comportamento econômico dos produtores. Piracicaba, FEALQ. Curso de Atualização em Confinamento de Bovinos de Corte.p.47-84, 1985.

PASTORE, A.C. A resposta da produção agricola aos presos no Brasiz. São Paulo, APEC, 1973. 170p. 
PEREZ, M.C.R.C. Contribuição do estudo da elasticidade-renda do consumo de alimentos. Piracicaba-SP, 1973. 94p. (Mestrado - Escola Superior de Agricultura "Luiz de Queiroz"/USP).

PHILIPS, L. Applied Consumption Analysis. North Holland, North Holland Publishing Company, 1983. 331p.

SANTOS, J.R.M.dos; BRANDT, S.A.; LADEIRA, H.H.; CAMPOS, J.R.S.; CARVALHO, W.L.de; PEDROSA, D.C.B.; AAD NETO, A. Perspectivas de consumo de carne bovina no mercado de São Luiz. 'Bo?etim SER, São Luiz, 1(2):24-51, 1974.

RIZZIERI, J.A.B. Estrutura de Ponderaçõés do Indice de Preços ao Consumidor do Município de São Paulo. FIPE - Fundação Instituto de Pesquisas Econômicas, São Paulo, 1987. (Mimeo,).

SERAPHTM, J.B.C. Análise econômica da procura de carnes no mercado de Goiânia, Estado de Goiâs. Viçosa, 1973. 84p. (Mestrado - Universidade Federal de Viçosa).

SEERIES ESTATISTICAS, Informações FIPE. São Paulo, nọ 106 - nov.1988.

SIMÕES, R.C. Estimativa de sistema de demanda de produtos agrícolas. Viçosa, 1980. 61p. (Mestrado - Universidade Federal de Viçosa). 
SIMS, C.A. Money, income and causality. American Economic Review. 62 (4):540-52, 1972 .

STROTZ, R.H. The empirical implications of a utility tree. Econométrica. Chicago, $27(3): 482-88,1959$.

TEIXEIRA, H.H.L. Modelo de desequilíbrio de margens de comercialização agrícola. Viçosa, 1982. 69p. (Mestrado-Universidade Federal de Viçosa). 